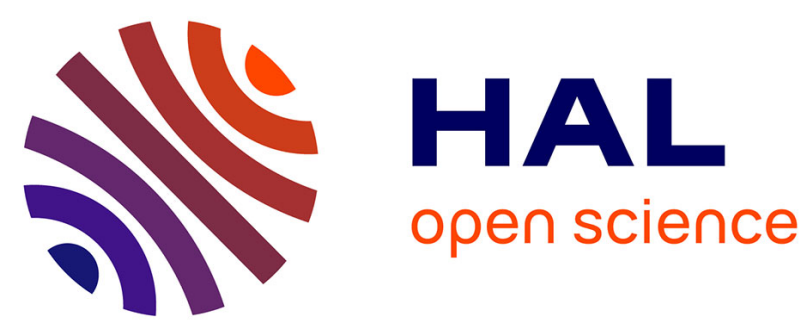

\title{
Optimal strategy based on radiation chemistry for facile and direct synthesis of poly(3-thiophene acetic acid) polymers in water and dichloromethane
}

Teseer Bahry, Zhenpeng Cui, Ariane Deniset-Besseau, Matthieu Gervais, Israël Mbomekalle, Cyrille Sollogoub, Pierre-Henri Aubert, Thanh-Tuân Bui, Samy Remita

\section{To cite this version:}

Teseer Bahry, Zhenpeng Cui, Ariane Deniset-Besseau, Matthieu Gervais, Israël Mbomekalle, et al.. Optimal strategy based on radiation chemistry for facile and direct synthesis of poly(3-thiophene acetic acid) polymers in water and dichloromethane. New Journal of Chemistry, 2020, 44 (27), pp.1165211666. 10.1039/d0nj01474e . hal-03001714

\section{HAL Id: hal-03001714 https://hal.science/hal-03001714}

Submitted on 12 Nov 2020

HAL is a multi-disciplinary open access archive for the deposit and dissemination of scientific research documents, whether they are published or not. The documents may come from teaching and research institutions in France or abroad, or from public or private research centers.
L'archive ouverte pluridisciplinaire HAL, est destinée au dépôt et à la diffusion de documents scientifiques de niveau recherche, publiés ou non, émanant des établissements d'enseignement et de recherche français ou étrangers, des laboratoires publics ou privés. 


\title{
Optimal strategy based on radiation chemistry for facile and direct synthesis of poly(3-thiophene acetic acid) polymers in water and dichloromethane
}

\author{
Teseer Bahry, ${ }^{a}$ Zhenpeng Cui, ${ }^{a}$ Ariane Deniset-Besseau, ${ }^{a}$ Matthieu Gervais, (D) ${ }^{b}$ \\ Israël Mbomekalle, ${ }^{a}$ Cyrille Sollogoub, (D) ${ }^{b}$ Pierre-Henri Aubert, ${ }^{c}$ \\ Thanh-Tuân Bui (D) ${ }^{c}$ and Samy Remita (D) *ad
}

\begin{abstract}
In this work, synthesis of nanostructured conducting poly(3-thiophene acetic acid) (PTAA) polymers was developed by means of $\gamma$-induced oxidative polymerization of TAA monomers dissolved either in water or in dichloromethane. This synthesis was shown to be facile and directly feasible without any prior esterification of TAA and in the absence of oxidizing agents. Radiolytic yields of TAA oxidation as well as irradiation doses required for quantitative PTAA preparation were determined for each solvent. UV-Vis and ATR-FTIR spectroscopies demonstrated the successful formation of two PTAA polymers, so-called "PTAA $\mathrm{H}_{2} \mathrm{O}$ " and "PTAA $\mathrm{CH}_{2} \mathrm{Cl}_{2}$ ". Size exclusion chromatography (SEC) highlighted convergent molecular weight values corresponding to approximately 13 monomer units. A similar behavior for both radiosynthesized PTAAs was monitored by thermogravimetric analysis (TGA). The morphological structures of PTAA $_{\mathrm{H}_{2} \mathrm{O}}$ and PTAA $\mathrm{CH}_{2} \mathrm{Cl}_{2}$ were analyzed in solution by Cryo-TEM and after deposition by SEM and AFM. Microscopic observations revealed the presence of two distinguishable nanostructures: nano-spherules of several hundreds of nanometers made of $\mathrm{PTAA}_{\mathrm{H}_{2} \mathrm{O}}$ and nano-granules of several tens of nanometers made of PTAA $\mathrm{CH}_{2} \mathrm{Cl}_{2}$. Cyclic voltammetry analysis and the Tauc plot method were employed to calculate the electrical and optical band gaps. Both polymers possess similar electrical band gaps. However, PTAA $\mathrm{CH}_{2} \mathrm{Cl}_{2}$ affords a lower optical band gap than PTAA $\mathrm{H}_{2} \mathrm{O}$. Four-point probe measurements showed that the radio-synthesized PTAA polymers are characterized by interesting electrical properties: a higher

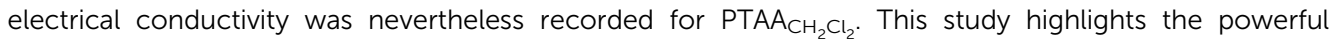
ability of the radiation chemistry-based methodology to lead, as a simple, versatile and reliable method, to nanostructured PTAA conducting polymers either in aqueous or organic solutions.
\end{abstract}

\section{Introduction}

Conducting polymers (CPs) have attracted a great deal of interest because of their excellent electrical conductivity, environmental stability and simplicity of synthesis. ${ }^{1-3}$ Thanks to these prominent and extraordinary properties, ${ }^{2}$ CPs have been used in several fields and integrated in many applications such

\footnotetext{
${ }^{a}$ Institut de Chimie Physique, ICP, UMR 8000, CNRS, Université Paris-Saclay, bâtiment 349, Campus d'Orsay, 15 avenue Jean Perrin, 91405 Orsay Cedex, France. E-mail: samy.remita@u-psud.fr; Tel: +33 (0)16915 30 28, +33 (0)169154441

${ }^{b}$ Laboratoire PIMM, Arts et Métiers Institute of Technology, CNRS, CNAM, Hesam université, F-75013 Paris Cedex, France

${ }^{c}$ CY Cergy Paris Université, LPPI, F95000 Cergy, France

${ }^{d}$ Département Chimie Vivant Santé, EPN 7, Conservatoire National des Arts et Métiers, CNAM, 292 rue Saint-Martin, 75141 Paris Cedex 03, France
}

as solar cells, ${ }^{4}$ light emitting diodes, ${ }^{5}$ field-transistors, ${ }^{6}$ etc. In this context, tremendous efforts have been made to develop and upgrade the synthesis methodologies of CPs, which are commonly polymerized either by electrochemical polymerization $^{7}$ or through chemical oxidation routes. ${ }^{8,9}$ Based on these conventional methods, numerous studies were carried out to optimize, to structuralize and to functionalize CPs. ${ }^{10}$ For this purpose, reverse micro-emulsion polymerization ${ }^{11,12}$ and CP composites with carbon nanotubes $(\mathrm{CNTs})^{13,14}$ have been employed to produce polymer nanotubes, ${ }^{15,16}$ wires, ${ }^{17}$ nanorods, ${ }^{18}$ fibers ${ }^{19}$ etc. Furthermore, polymer-metal oxide nanocomposites were used to enhance their thermal, mechanical and chemical properties. ${ }^{20,21}$ However, these methods cause problems such as metal contamination due to the use of metal compounds as catalysts in the case of chemical methods and the mandatory use of conducting electrodes in the case of electrochemical methods. 
For the sake of simplifying the preparation of nanostructured CPs, finding an alternative synthesis method would be immensely helpful. In this context, based on the use of soft templates, poly(3,4-ethylenedioxythiophene), PEDOT, poly(3-hexylthiophene), P3HT, and polypyrrole (PPy) were successfully synthesized in hexagonal mesophases. ${ }^{22-24}$ In another regard, ionizing radiation induced polymerization is not commonly used in the field of CP nanostructure synthesis. ${ }^{25}$ In previous studies, our group has developed a new methodology based on radiation chemistry to polymerize some of those CPs in aqueous solutions thanks to the oxidation of dissolved organic monomers by solvent radicals in situ produced in the medium during water radiolysis. ${ }^{26-30}$ Quite recently, our strategy based on radiation chemistry was opened up to the preparation of conducting polymers in organic solvents. ${ }^{31}$ As an adequate solvent, dichloromethane is able to dissolve a wide range of organic compounds and besides irradiated dichloromethane is a good oxidizing system. ${ }^{32}$ Moreover, gamma-induced oxidative polymerization in dichloromethane was successfully employed to polymerize 3,4-ethylenedioxythiophene into poly(3,4-ethylenedioxythiophene) (PEDOT) polymers. ${ }^{31}$

In this context, poly(3-thiophene acetic acid), PTAA, as one of the most important polythiophene derivative members, is an excellent and practical conducting polymer due to its various interesting properties such as high conductivity, good thermal and environmental stability, and biocompatibility. ${ }^{33}$ The particular importance and usefulness of this conjugated material result from the presence of the carboxyl acid moiety all along the polymer chains. PTAA polymers are appropriate for the preparation of nanocomposites based on conjugated polymers and metal oxides, in particular $\mathrm{PTAA}-\mathrm{Fe}_{3} \mathrm{O}_{4}$ nanocomposites. ${ }^{20,34-36}$ Carboxyl acid functional groups also offer better adsorption and better surface contact between sensitizing polymer molecules such as PTAA and other incorporated molecules such as mesoporous $\mathrm{TiO}_{2}{ }^{37}$ Furthermore, the carboxyl acid groups present all along PTAA polymer chains are considered as $\mathrm{pH}$ responsive groups ${ }^{38}$ and are well used for the preparation of charge-selective films. ${ }^{39}$ It has also been shown by McCullough et al. that regioregular water-soluble polythiophenes with a propionic acid at the 3-position of a thiophene ring can switch from purple to yellow phases by increasing the amount of $\mathrm{NH}_{4} \mathrm{OH}$ in aqueous solution. ${ }^{40}$

While the PTAA polymer is engaged in many sophisticated applications and appears as a very promising material, its synthesis is not so easy by the way of conventional methods. Indeed, there are many issues towards the synthesis of this polymer either by chemical or electrochemical methods. By the way of chemical methods, an esterification reaction is essential to a priori protect the carboxylic acid moiety of TAA monomers from oxidative decomposition. ${ }^{37,38}$ Then several steps are required to accomplish the synthesis. Moreover, TAA has limited solubility in conventional aqueous media and its oxidation potential is higher than that of water decomposition. As a consequence, by the way of electrochemical methods, PTAA can't be produced in water and is mainly electropolymerized in organic media such as boron triflouride diethyletherate (BFEE) and trifluoroacetic (TFA). ${ }^{33,41-43}$

Therefore, with this in mind and based on our previous radiation chemistry-based methodologies, we report here for

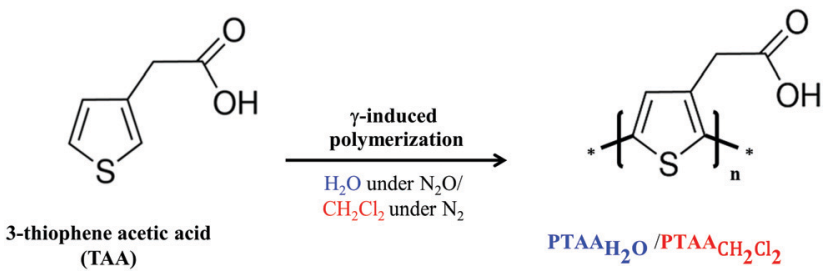

Scheme 1 One step synthesis of poly(3-thiophene acetic acid) (PTAA) via $\gamma$-radiolysis of water and dichloromethane.

the first time the use of two different radiolytic routes to induce the oxidative polymerization of 3-thiophene acetic acid (TAA) in a one step synthesis, starting from monomers dissolved either in water or in dichloromethane and without using oxidizing agents or any prior esterification (Scheme 1). In this work, we present a simple way to synthesize and then to modulate the morphological nanostructures of PTAA conducting polymers $\left(\mathrm{PTAA}_{\mathrm{H}_{2} \mathrm{O}}\right.$ and $\mathrm{PTAA}_{\mathrm{CH}_{2} \mathrm{Cl}_{2}}$ ) thanks to the use of oxidizing species generated from $\gamma$-radiolysis of water and dichloromethane solvents. Then, detailed comparative studies of the optical and electrical properties are carried out between the two radio-synthesized PTAA $\mathrm{H}_{2} \mathrm{O}$ and $\mathrm{PTAA}_{\mathrm{CH}_{2} \mathrm{Cl}_{2}}$.

\section{Experimental}

\subsection{Reagents and solvents}

3-Thiopheneacetic acid, TAA (98\%), was purchased from SigmaAldrich and used as a monomer. Dichloromethane (DCM) anhydrous $(\geq 99.8 \%)$, acetonitrile $(\mathrm{ACN})(\geq 99.9 \%)$ and the other used solvents were purchased from Sigma-Aldrich. Also, distilled water (Millipore system $18.2 \Omega \mathrm{cm}^{-1}$ ) was used as a solvent and for washing. $\mathrm{N}_{2}$ gas (Air Liquid Co.) was used to deaerate dichloromethane solutions. $\mathrm{N}_{2} \mathrm{O}$ (Air Liquid Co.) was used to degas the aqueous solutions of TAA before $\gamma$-irradiation. Nitrosyl tetrafluoroborate $\left(\mathrm{NOBF}_{4}\right) \quad(\geq 95 \%$, Sigma-Aldrich) dissolved in acetonitrile was used as a dopant during the electrical conductivity measurements. All compounds were used as received. All experiments were performed at room temperature.

\subsection{Solution preparation}

Dichloromethane solutions containing 10 mM TAA monomers were prepared at room temperature. Note that the used concentration is lower than the TAA solubility in dichloromethane at $25{ }^{\circ} \mathrm{C}$ (which is over $50 \mathrm{mM}$ as found by UV-Vis absorption spectroscopy study). This concentration remains also much lower than the dichloromethane molecule concentration (15.6 M). This enables one to neglect the direct effect of ionizing radiation on TAA monomers.

In the same manner, aqueous solutions containing $10 \mathrm{mM}$ TAA were prepared at room temperature. The chosen TAA concentration, which is lower than the TAA solubility in water, was always checked by UV-Vis absorption spectroscopy.

Dichloromethane and aqueous solutions were degassed respectively with $\mathrm{N}_{2}$ and $\mathrm{N}_{2} \mathrm{O}$ for $20 \mathrm{~min}$, sealed in glass 
ampoules and then irradiated with a ${ }^{60} \mathrm{Co} \gamma$-source at doses up to $38 \mathrm{kGy}$ and at a dose rate of $4.1 \mathrm{kGy} \mathrm{h}^{-1}$.

\subsection{Dichloromethane radiolysis and radiation induced synthesis of $\mathrm{PTAA}_{\mathrm{CH}_{2} \mathrm{Cl}_{2}}$}

The radiolysis of deoxygenated dichloromethane within a short nanosecond time scale generates solvated electrons in addition to chloride radicals and solvent radical cations, which quickly yield dichloromethyl $\left(\mathrm{CHCl}_{2}^{\bullet}\right)$ and chloromethyl $\left(\mathrm{CH}_{2} \mathrm{Cl}^{\bullet}\right)$ radicals: $:^{44,45}$

$\mathrm{CH}_{2} \mathrm{Cl}_{2} \rightarrow \rightarrow\left[\mathrm{e}^{-}+\mathrm{Cl}^{\bullet}+\mathrm{CH}_{2} \mathrm{Cl}_{2}^{\bullet+}\right] \rightarrow \rightarrow \mathrm{CHCl}_{2}^{\bullet}+\mathrm{CH}_{2} \mathrm{Cl}^{\bullet}+\mathrm{HCl}$

All the finally generated radicals are well known as strong oxidizing species towards organic materials. ${ }^{32}$

As demonstrated in our previous study, ${ }^{31}$ gamma induced oxidative polymerization of EDOT can be initiated by the generated oxidizing species in dichloromethane under an $\mathrm{N}_{2}$ atmosphere and furthermore the total yield of EDOT oxidation, $G_{\text {ox }}$, amounts to $4.12 \times 10^{-7} \mathrm{~mol} \mathrm{~J}^{-1}$. As a consequence, in the same experimental conditions, in dichloromethane under an $\mathrm{N}_{2}$ atmosphere, we can assume that the yield of TAA oxidation has the same value $\left(4.12 \times 10^{-7} \mathrm{~mol} \mathrm{~J}^{-1}\right)$.

The concentration of TAA oxidized through dichloromethane radiolysis can be expressed as a function of the irradiation dose, $D$, expressed in Gray (Gy, 1 Gy corresponds to $1 \mathrm{~J} \mathrm{~kg}^{-1}$ ) according to:

[Oxidized TAA] $\left(\mathrm{mol} \mathrm{L}^{-1}\right)=D(\mathrm{~Gy}) \times G_{\mathrm{ox}}\left(\mathrm{mol} \mathrm{J}^{-1}\right) \times d\left(\mathrm{~kg} \mathrm{~L}^{-1}\right)$

where $G_{\text {ox }}$ is the effective yield of TAA oxidation and where $d$ is the dichloromethane density $\left(d=1.35 \mathrm{~kg} \mathrm{~L}^{-1}\right)$.

As stated by our previous kinetic studies ${ }^{29,30}$ and demonstrated in our previous work in dichloromethane solvent, ${ }^{31}$ for quantitative production of $\mathrm{PTAA}_{\mathrm{CH}_{2} \mathrm{Cl}_{2}}$, the concentration of oxidative species produced by radiolysis should be twice that of TAA monomers. Also, the dose, $D_{\text {max }}$, needed for quantitative preparation of $\mathrm{PTAA}_{\mathrm{CH}_{2} \mathrm{Cl}_{2}}$ in dichloromethane under an $\mathrm{N}_{2}$ atmosphere is twice the dose necessary for the total oxidation of TAA monomers and can be expressed and calculated according to:

$$
D_{\max }(\mathrm{Gy})=\frac{2\left[\mathrm{TAA}_{0}\left(\mathrm{~mol} \mathrm{~L}^{-1}\right)\right.}{G_{\mathrm{ox}}\left(\mathrm{mol} \mathrm{J}^{-1}\right) \times d\left(\mathrm{~kg} \mathrm{~L}^{-1}\right)}
$$

where $[\mathrm{TAA}]_{0}$ is the initial concentration of TAA monomers.

Thus, the dose which is necessary for the total oxidation of $10 \mathrm{mM}$ TAA amounts to $18 \mathrm{kGy}$, while the dose $D_{\max }$ which is necessary for the complete synthesis of PTAA $\mathrm{CH}_{2} \mathrm{Cl}_{2}$ amounts to 36 kGy.

As stated by our previous study, ${ }^{31}$ indeed, the dose of $36 \mathrm{kGy}$ is the optimal irradiation dose which enables quantitative polymerization of $10 \mathrm{mM}$ monomers. Above this irradiation dose, overoxidation is systematically observed, which leads to the degradation of CP chains. In this context, a solution of dichloromethane containing $10 \mathrm{mM}$ TAA under an $\mathrm{N}_{2}$ atmosphere was irradiated at doses up to $36 \mathrm{kGy}\left(D_{\max }\right)$. After $\gamma$-irradiation, in order to record the UV-Vis absorption spectrum of the $\mathrm{PTAA}_{\mathrm{CH}_{2} \mathrm{Cl}_{2}}$ polymer, the irradiated solution was naturally dried under a fume hood to remove the produced organochloride products. Later, the UV-Vis absorption spectrum was recorded by adding $1 \mathrm{~mL}$ of dichloromethane to the black precipitates.

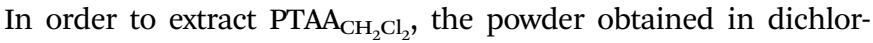
omethane at $36 \mathrm{kGy}$ was centrifuged at a speed of $13 \times$ $10^{+3} \mathrm{rpm} \mathrm{s}^{-1}$ for $20 \mathrm{~min}$. Later, the supernatant was discarded and then the precipitate was placed in an oven for desiccation at $50{ }^{\circ} \mathrm{C}$ for $24 \mathrm{~h}$ and lastly $\mathrm{PTAA}_{\mathrm{CH}_{2} \mathrm{Cl}_{2}}$ powder was then used for further characterization and spectral analysis.

\subsection{Water radiolysis and radiation induced synthesis of PTAA $_{\mathrm{H}_{2} \mathrm{O}}$}

It is well-established that with a nanosecond time scale, the irradiation of deoxygenated aqueous solutions with ionizing radiation at neutral $\mathrm{pH}(\mathrm{pH} \approx 7)$ generates the following various radiolytic species: ${ }^{46-48}$

$$
\mathrm{H}_{2} \mathrm{O} \rightsquigarrow \mathrm{e}_{\mathrm{aq}}{ }^{-}, \mathrm{HO}^{\bullet}, \mathrm{H}^{\bullet}, \mathrm{H}_{3} \mathrm{O}^{+}, \mathrm{H}_{2} \mathrm{O}_{2}, \mathrm{H}_{2}
$$

Under these experimental conditions, the radiolytic yields for the formation of the different radical species are well known: ${ }^{46-48}$ $G_{\mathrm{HO}^{\bullet}}=2.8 \times 10^{-7} \mathrm{~mol} \mathrm{~J}^{-1}, G_{\mathrm{H}^{\bullet}}=0.6 \times 10^{-7} \mathrm{~mol} \mathrm{~J}^{-1}$ and $G_{\mathrm{e}_{\mathrm{aq}}}{ }^{-}=$ $2.8 \times 10^{-7} \mathrm{~mol} \mathrm{~J}^{-1}$.

In the presence of $\mathrm{N}_{2} \mathrm{O}, \mathrm{e}_{\mathrm{aq}}{ }^{-}$is efficiently converted into hydroxyl radical, $\mathrm{HO}^{\bullet}$, through the following reaction: ${ }^{46,47}$

$$
\mathrm{e}_{\mathrm{aq}}{ }^{-}+\mathrm{N}_{2} \mathrm{O}+\mathrm{H}_{2} \mathrm{O} \rightarrow \mathrm{HO}^{\bullet}+\mathrm{HO}^{-}+\mathrm{N}_{2}
$$

Thus, in neutral aqueous medium under $\mathrm{N}_{2} \mathrm{O}$, the radiolytic yield of formation of $\mathrm{HO}^{\bullet}$ amounts to:

$$
G_{\left(\mathrm{HO}^{\bullet}\right)}=G_{\mathrm{HO}} \cdot+G_{\mathrm{e}_{\mathrm{aq}}}{ }^{-}=5.6 \times 10^{-7} \mathrm{~mol} \mathrm{~J}^{-1}
$$

$\mathrm{HO}^{\bullet}$ radicals are known to be strong oxidizing species since their apparent standard redox potential at $\mathrm{pH}=7$ amounts to $E^{\circ \prime}\left(\mathrm{HO}^{\bullet} / \mathrm{H}_{2} \mathrm{O}\right)=2.2 \mathrm{~V}_{\mathrm{SHE}}{ }^{48}$ Also, hydroxyl radicals $\left(\mathrm{HO}^{\bullet}\right)$ under these experimental conditions are the most abundant species with high reactivity. On the other hand, it is well known that $\mathrm{e}_{\mathrm{aq}}{ }^{-}$(which are partly scavenged by $\mathrm{HO}^{\bullet}$ ) and $\mathrm{H}^{\bullet}$ are very reducing species with a redox potential of $-2.8 \mathrm{~V}_{\mathrm{SHE}}$ and $-2.3 \mathrm{~V}_{\text {SHE}}$, respectively. ${ }^{49,50}$

In this study, it is important to mention that the $\mathrm{pH}$ of TAA aqueous solutions is acidic and amounts to roughly 2.7. It was demonstrated that as the $\mathrm{pH}$ of the aqueous solution decreases, $\mathrm{e}_{\mathrm{aq}}{ }^{-}$reacts with hydrogen ions $\left(\mathrm{H}^{+}\right)$in the acidic medium ${ }^{46}$ according to:

$$
\mathrm{e}_{\mathrm{aq}}{ }^{-}+\mathrm{H}^{+} \rightarrow \mathrm{H}^{\bullet}
$$

In this regard, there are two competitive reactions (5) and (7) involving $\mathrm{e}_{\mathrm{aq}}{ }^{-}$: first with $\mathrm{N}_{2} \mathrm{O}$ which leads to additional $\mathrm{HO}^{\bullet}$ radicals (reaction (5)) and second with $\mathrm{H}^{+}$which leads to additional $\mathrm{H}^{\bullet}$ radicals (reaction (7)). Keeping that in mind, the radiolytic yield of formation of $\mathrm{HO}^{\bullet}$ no longer corresponds to eqn (6). Nevertheless, we demonstrated in one of our previous studies ${ }^{51}$ that it is possible to calculate the new radiolytic yield of $\mathrm{HO}^{\bullet}$ in acidic medium from the branching 
ratio between reactions (5) and (7), as expressed in the following eqn (8):

$$
R=\frac{G_{\mathrm{HO}} \cdot}{G_{\mathrm{H}^{\prime}}}=\frac{k_{\mathrm{N}_{2} \mathrm{O}}\left[\mathrm{N}_{2} \mathrm{O}\right]}{k_{\mathrm{H}^{+}}\left[\mathrm{H}^{+}\right]}
$$

where $\left[\mathrm{N}_{2} \mathrm{O}\right]$ and $\left[\mathrm{H}^{+}\right]$are the concentrations of $\mathrm{N}_{2} \mathrm{O}$ and $\mathrm{H}^{+}$ respectively, where $k_{\mathrm{N}_{2} \mathrm{O}}$ and $k_{\mathrm{H}^{+}}$are the rate constants of reactions (5) and (7) respectively and where $G_{\mathrm{HO}^{\circ}}{ }^{\prime}$ and $G_{\mathrm{H}^{\circ}}$ are the radiolytic yields of production of the additional amounts of $\mathrm{HO}^{\bullet}$ and $\mathrm{H}^{\bullet}$ according to reactions (5) and (7). Note that:

$$
G_{\mathrm{HO}} \cdot^{\prime}+G_{\mathrm{H}^{\cdot}}{ }^{\prime}=G_{\mathrm{e}_{\mathrm{aq}}{ }^{-}}=2.8 \times 10^{-7} \mathrm{~mol} \mathrm{~J}^{-1}
$$

Keeping in mind that $\left[\mathrm{N}_{2} \mathrm{O}\right]=2.65 \times 10^{-2} \mathrm{~mol} \mathrm{~L}^{-1}$ and $\left[\mathrm{H}^{+}\right]=$ $10^{-\mathrm{pH}}=1.99 \times 10^{-3} \mathrm{~mol} \mathrm{~L}^{-1}$ and knowing that the rate constants $k_{\mathrm{N}_{2} \mathrm{O}}$ and $k_{\mathrm{H}^{+}}$are equal to $9 \times 10^{9} \mathrm{~L} \mathrm{~mol}^{-1} \mathrm{~s}^{-1}$ and $2.3 \times 10^{10} \mathrm{~L} \mathrm{~mol}^{-1} \mathrm{~s}^{-1}$, respectively, ${ }^{52}$ the branching ratio $(R)$ at $\mathrm{pH} \approx 2.7$ can be estimated: $R=5.2$. According to eqn (8) and (9), one can calculate the corresponding radiolytic yields: $G_{\mathrm{HO}}{ }^{\prime}=2.4 \times 10^{-7} \mathrm{~mol} \mathrm{~J}^{-1}$ and $G_{\mathrm{H}^{\circ}}{ }^{\prime}=0.4 \times 10^{-7} \mathrm{~mol} \mathrm{~J}^{-1}$.

It is then possible to evaluate, under $\mathrm{N}_{2} \mathrm{O}$ at $\mathrm{pH} \approx 2.7$, the total radiolytic yields of production of $\mathrm{HO}^{\bullet}$ radicals and of $\mathrm{H}^{\bullet}$ atoms according to:

$$
\begin{aligned}
G\left(\mathrm{HO}^{\bullet}\right) & =G_{\mathrm{HO}} \cdot+G_{\mathrm{HO}}{ }^{\prime}=5.2 \times 10^{-7} \mathrm{~mol} \mathrm{~J}^{-1} \\
G\left(\mathrm{H}^{\bullet}\right) & =G_{\mathrm{H}^{\bullet}}+G_{\mathrm{H}^{\bullet}}=1.0 \times 10^{-7} \mathrm{~mol} \mathrm{~J}^{-1}
\end{aligned}
$$

Hence, at this relatively moderate $\mathrm{pH}$ value $(\approx 2.7)$, the radiolytic yield of $\mathrm{HO}^{\bullet}\left(5.2 \times 10^{-7} \mathrm{~mol} \mathrm{~J}^{-1}\right)$ is still much higher than that of $\mathrm{H}^{\bullet}\left(1.0 \times 10^{-7} \mathrm{~mol} \mathrm{~J}^{-1}\right.$ at $\left.\mathrm{pH} \approx 2.7\right)$. So, the presence and reactivity of hydrogen atoms, $\mathrm{H}^{*}$, will be neglected in the present work.

Consequently, the concentration of hydroxyl radicals [HO] produced by water radiolysis can then be expressed as a function of the irradiation dose, $D$, expressed in Gray according to:

$$
\left[\mathrm{HO}^{\bullet}\right]\left(\mathrm{mol} \mathrm{L}^{-1}\right)=D(\mathrm{~Gy}) \times G\left(\mathrm{HO}^{\bullet}\right)\left(\mathrm{mol} \mathrm{J}^{-1}\right) \times d\left(\mathrm{~kg} \mathrm{~L}^{-1}\right)
$$

where $d$ is the water density $\left(d=1 \mathrm{~kg} \mathrm{~L}^{-1}\right)$. In a like manner to our previous studies, ${ }^{26-28}$ the theoretical irradiation dose $\left(D_{\max }\right)$ that should lead to the quantitative formation of $\mathrm{PTAA}_{\mathrm{H}_{2} \mathrm{O}}$ in aqueous solutions is twice the dose necessary for the total oxidation of TAA monomers (by $\mathrm{HO}^{\bullet}$ radicals) in water under $\mathrm{N}_{2} \mathrm{O}$ and can be calculated as mentioned below and thus amounts to $38 \mathrm{kGy}$ for $10 \mathrm{mM}$ TAA:

$$
D_{\max }(\mathrm{Gy})=\frac{2[\mathrm{TAA}]_{0}\left(\mathrm{~mol} \mathrm{~L}^{-1}\right)}{G\left(\mathrm{HO}^{\bullet}\right)\left(\mathrm{mol} \mathrm{J}^{-1}\right) \times d\left(\mathrm{~kg} \mathrm{~L}^{-1}\right)}
$$

Note that the two doses required for quantitative production of PTAA $_{\mathrm{H}_{2} \mathrm{O}}(38 \mathrm{kGy})$ and $\mathrm{PTAA}_{\mathrm{CH}_{2} \mathrm{Cl}_{2}}(36 \mathrm{kGy})$ are very close to each other. Hence, an aqueous solution of $10 \mathrm{mM}$ TAA under an $\mathrm{N}_{2} \mathrm{O}$ atmosphere was prepared and then irradiated at doses up to $38 \mathrm{kGy}$. After irradiation, the UV-Vis absorption spectrum was directly recorded for the resulting suspension. In order to extract $\mathrm{PTAA}_{\mathrm{H}_{2} \mathrm{O}}$ polymers and to evaporate water, the irradiated solution was centrifuged at a speed of $13 \times 10^{3} \mathrm{rpm} \mathrm{s}^{-1}$ for $20 \mathrm{~min}$.
Later, the supernatant was discarded and then the precipitate was placed in an oven for drying at $50{ }^{\circ} \mathrm{C}$ for $24 \mathrm{~h}$. The obtained PTAA $_{\mathrm{H}_{2} \mathrm{O}}$ powders were then directly used for further characterization and spectral analysis.

\subsection{Characterization methods}

- UV-Vis absorption spectroscopy. UV-Vis absorption spectroscopy was used to check the optical properties of TAA monomers and those of $\mathrm{PTAA}_{\mathrm{CH}_{2} \mathrm{Cl}_{2}}$ and $\mathrm{PTAA}_{\mathrm{H}_{2} \mathrm{O}}$ polymers radio-synthesized in dichloromethane and water at increasing doses. An HP 8543 spectrophotometer was used to measure the absorbance of the solutions before and after irradiation. The apparatus covers a wide range of wavelengths, starting from $200 \mathrm{~nm}$ in the UV region to $1200 \mathrm{~nm}$ in the near-infrared region. A quartz cell with an optical pathlength of $2 \mathrm{~mm}$ was used to perform all the measurements. The reference was always the pure solvent.

- Attenuated total reflectance Fourier transform infrared (ATR-FTIR) spectroscopy. FTIR was used for further chemical characterization of $\mathrm{PTAA}_{\mathrm{CH}_{2} \mathrm{Cl}_{2}}$ and $\mathrm{PTAA}_{\mathrm{H}_{2} \mathrm{O}}$ polymers. The dried polymers were deposited and squeezed on the ATR support of the FTIR spectrophotometer. Measurements were made by using a Bruker Vertex 70 FTIR spectrophotometer with a diamond ATR support (PIKE MIRACLE crystal plate diamond/ ZnSe) and MCT detector using a liquid nitrogen cooling system. The scanning was conducted from 4000 to $600 \mathrm{~cm}^{-1}$ with a $4 \mathrm{~cm}^{-1}$ spectral resolution and accumulation 100 times.

- Size exclusion chromatography (SEC). SEC was used in order to check the average molecular weight of $\mathrm{PTAA}_{\mathrm{CH}_{2} \mathrm{Cl}_{2}}$ and PTAA $_{\mathrm{H}_{2} \mathrm{O}}$ polymers. For this purpose, solutions of $3 \mathrm{mg} \mathrm{L}^{-1}$ of PTAA $_{\mathrm{CH}_{2} \mathrm{Cl}_{2}}$ and $\mathrm{PTAA}_{\mathrm{H}_{2} \mathrm{O}}$ were prepared in THF and then $100 \mu \mathrm{L}$ of each THF solution was injected into the SEC apparatus. Using THF as the eluent, SEC was performed at $40{ }^{\circ} \mathrm{C}$ on a Malvern Viscotek TDA apparatus equipped with two columns, Malvern T3000 and T6000, with a Malvern refractive index detector at an elution rate of $1 \mathrm{~mL} \mathrm{~min}^{-1}$. Polystyrene polymers were used as standards.

- Cryogenic-transmission electron microscopy (Cryo-TEM). In order to check the morphology of $\mathrm{PTAA}_{\mathrm{CH}_{2} \mathrm{Cl}_{2}}$ and $\mathrm{PTAA}_{\mathrm{H}_{2} \mathrm{O}}$ polymers dispersed in $\mathrm{CH}_{2} \mathrm{Cl}_{2}$ and in aqueous solutions, Cryo-TEM microscopy was used. For proper comparison, two solutions at concentration $3 \mathrm{mg} \mathrm{mL}{ }^{-1}$ were prepared in water and dichloromethane for the corresponding polymers $\mathrm{PTAA}_{\mathrm{H}_{2} \mathrm{O}}$ and $\mathrm{PTAA}_{\mathrm{CH}_{2} \mathrm{Cl}_{2}}$, respectively. The observations were carried out on a transmission electron microscope in a cryogenic environment (Cryo-TEM), known to be adapted to low density contrasts. A drop of each prepared solution, containing $\mathrm{PTAA}_{\mathrm{H}_{2} \mathrm{O}}$ or PTAA $_{\mathrm{CH}_{2} \mathrm{Cl}_{2}}$, was deposited on "Quantifoil" (Quantifoil Micro Tools Gmbh, Germany) 200 mesh holey-carbon-coated grids. After being blotted with filter paper, the grids were quench-frozen by being rapidly plunged into liquid ethane in order to form a thin ice film avoiding water crystallization or a thin frozen dichloromethane film avoiding dichloromethane crystallization. The grids were then transferred into the microscope using a side entry Gatan 626 cryoholder cooled at $-180^{\circ} \mathrm{C}$ with liquid nitrogen in order to image $\mathrm{PTAA}_{\mathrm{H}_{2} \mathrm{O}}$ and $\mathrm{PTAA}_{\mathrm{CH}_{2} \mathrm{Cl}_{2}}$ polymers. Images were recorded 
with an Ultrascan 2k CCD camera (Gatan, USA) by using a LaB6 JEOL JEM 2100 (JEOL, Japan) cryo-microscope operating at $200 \mathrm{kV}$ with a low-dose system (Minimum Dose System, MDS) to protect the thin films from any irradiation before imaging and to reduce the irradiation during image capture. By freezing the system, Cryo-TEM ensures the observation of soft nano-objects in equilibrium in aqueous and dichloromethane solutions since it avoids the phase transition and possible $\mathrm{PTAA}_{\mathrm{H}_{2} \mathrm{O}}$ or $\mathrm{PTAA}_{\mathrm{CH}_{2} \mathrm{Cl}_{2}}$ polymer aggregation resulting from drying procedures.

- Scanning electron microscopy (SEM) and energy-dispersive $\mathrm{X}$-ray spectroscopy (EDX). In order to investigate the structure of the radio-synthesized $\mathrm{PTAA}_{\mathrm{H}_{2} \mathrm{O}}$ and $\mathrm{PTAA}_{\mathrm{CH}_{2} \mathrm{Cl}_{2}}$ polymers and to check their morphology after deposition, the dried polymer powders were sprinkled, after solvent evaporation, onto carbon tape adhered to aluminum mounts and then coated with gold in order to get high imaging resolution. The SEM observations were performed by using an EVO MA 10 ZEISS microscope supplied with SMRT SEM as a piloting program. The functioning pressure was 105 Torr, the applied voltage was $15 \mathrm{kV}$ and the scale bars were 2, 10 and $20 \mu \mathrm{m}$. In situ EDX was carried out without a gold coating to identify the chemical composition of the materials and to perform elemental analysis within a selected area of the samples.

- Atomic force microscopy coupled with infrared nanospectroscopy (AFM-IR). AFM-IR was used to check whether the PTAA $_{\mathrm{H}_{2} \mathrm{O}}$ and $\mathrm{PTAA}_{\mathrm{CH}_{2} \mathrm{Cl}_{2}}$ polymers maintain their original morphology during the drying process. In this context, $3 \mathrm{mg}$ of dried polymer powder was dissolved in $2 \mathrm{~mL}$ of ethanol. A small drop of each ethanolic solution was deposited onto the upper surface of a $\mathrm{CaF}_{2}$ disk and dried under He. The AFM (nanoIR, Anasys Instruments Corp, Bruker NANO Group, California, USA) was used in tapping mode with a $40 \mathrm{~N} \mathrm{~m}^{-1}$ silicon cantilever (PPP-NCLR-50, nanosensors, Neuchâtel, Switzerland).

- X-Ray diffraction (XRD) analysis. XRD analysis was used to check the crystallinity of the PTAA $\mathrm{CH}_{2} \mathrm{Cl}_{2}$ and $\mathrm{PTAA}_{\mathrm{H}_{2} \mathrm{O}}$ polymers synthesized by gamma radiolysis of $\mathrm{CH}_{2} \mathrm{Cl}_{2}$ and water solutions at an irradiation dose of $36 \mathrm{kGy}$ and $38 \mathrm{kGy}$ respectively. The PTAA $_{\mathrm{H}_{2} \mathrm{O}}$ and $\mathrm{PTAA}_{\mathrm{CH}_{2} \mathrm{Cl}_{2}}$ polymers were crushed and handmilled in order to obtain fine powders, which were then used for XRD characterization (PANalytical X'pert pro MPD with an $\mathrm{X}$ 'celerator acquisition system). $\mathrm{Cu} \mathrm{K} \alpha 1(\lambda=1.54059 \AA)$ radiation was used as the X-ray source. A scanning rate of $0.0015^{\circ} \mathrm{s}^{-1}$ was employed to perform $\theta-2 \theta$ scans from $10^{\circ}$ to $80^{\circ}$.

- Thermogravimetric (TGA) analysis. Thermal stability and composition analysis of the $\mathrm{PTAA}_{\mathrm{CH}_{2} \mathrm{Cl}_{2}}$ and $\mathrm{PTAA}_{\mathrm{H}_{2} \mathrm{O}}$ polymers synthesized in $\mathrm{CH}_{2} \mathrm{Cl}_{2}$ and water solutions (at an irradiation dose of $36 \mathrm{kGy}$ and $38 \mathrm{kGy}$ respectively) were performed on a thermogravimetric analysis instrument TGA Q500 (TA Instruments, USA) under a nitrogen flow of $50 \mathrm{~mL} \min ^{-1}$. In this context, a few mg of dried PTAA $\mathrm{H}_{2} \mathrm{O}$ and $\mathrm{PTAA}_{\mathrm{CH}_{2} \mathrm{Cl}_{2}}$ polymer powder was used. The temperature ranged from 25 to $800{ }^{\circ} \mathrm{C}$ at a heating rate of $10{ }^{\circ} \mathrm{C} \mathrm{min}^{-1}$.

- Cyclic-voltammetry measurements (CV). The electrochemical setup was a three-electrode cell, with a Pt disk of $1 \mathrm{~mm}$ diameter as the working electrode, Pt wire in a separate compartment as the counter electrode and a saturated calomel electrode (SCE) in a separate compartment as the reference electrode. The latter was calibrated as recommended by IUPAC probing the ferrocenium/ferrocene $\left(\mathrm{Fc}^{+} / \mathrm{Fc}\right)$ redox potential measured at the end of each experiment. Solutions of $\mathrm{PTAA}_{\mathrm{H}_{2} \mathrm{O}}$ and $\mathrm{PTAA}_{\mathrm{CH}_{2} \mathrm{Cl}_{2}}$ polymers at a concentration of $3 \mathrm{mg} \mathrm{mL}^{-1}$ in THF were used. Later the electrodes were immersed into an electrochemical cell containing acetonitrile with $0.1 \mathrm{~mol} \mathrm{~L}^{-1}$ tetrabutylammonium hexafluorophosphate $\left(\mathrm{TBAPF}_{6}\right)$. The cyclic voltammograms of the compounds were recorded at a scan rate of $100 \mathrm{mV} \mathrm{s}^{-1}$ between $-2.5 \mathrm{~V}$ and $+2.5 \mathrm{~V}$.

- Electrical conductivity measurements by the four-point probe technique. To measure the conductivity of the $\mathrm{PTAA}_{\mathrm{H}_{2} \mathrm{O}}$ and $\mathrm{PTAA}_{\mathrm{CH}_{2} \mathrm{Cl}_{2}}$ polymers, the four-point probe technique was used. PTAA $\mathrm{H}_{2} \mathrm{O}$ and $\mathrm{PTAA}_{\mathrm{CH}_{2} \mathrm{Cl}_{2}}$ powders obtained after irradiation and solvent evaporation were dissolved in $\mathrm{CH}_{2} \mathrm{Cl}_{2}$ at a concentration of $10 \mathrm{mg} \mathrm{mL}{ }^{-1}$. The solutions were then stirred for $48 \mathrm{~h}$ to ensure complete dispersity and homogeneity. Later, $100 \mu \mathrm{L}$ of the solutions was spin-coated on a clean glass substrate at a speed of $100 \mathrm{rpm}$ for $60 \mathrm{~s}$. Afterwards, the PTAA films were rinsed and doped with $\mathrm{NOBF}_{4}$ at a concentration of $10 \mathrm{mM}$ in acetonitrile and then the substrates were placed on a hot plate and heated up to $130{ }^{\circ} \mathrm{C}$ for $30 \mathrm{~min}$ in order to dry and evaporate the remaining solvent. A 3 Veeco Dektak 150 surface profiler was used for thickness measurements of the PTAA films, while a Kelvin four-point probe technique was used for measuring the resistance of the films. The conductivity, $\rho$ $\left(\mathrm{S} \mathrm{cm}^{-1}\right)$, was determined thanks to the following equation:

$$
\rho=\left(\frac{\pi}{\ln 2} \times \frac{V}{I} \times t\right)^{-1}
$$

where $V$ is the voltage difference $(\mathrm{V}), t$ the film thickness $(\mathrm{cm})$ and $I$ the applied current (A).

\section{Results and discussion}

\subsection{Radiation induced synthesis of PTAAs in water and in dichloromethane}

Aqueous and dichloromethane solutions containing $10 \mathrm{mM}$ TAA were prepared (under $\mathrm{N}_{2} \mathrm{O}$ and $\mathrm{N}_{2}$ respectively). Their representative UV-Vis absorption spectra recorded before irradiation are displayed in the inset of Fig. 1a and b. Typically, thiophene molecules usually absorb light in the UV region between 225 and $245 \mathrm{~nm}$, and this absorption is ascribed to a $\pi-\pi^{*}$ transition. ${ }^{53}$ Indeed, the UV-Vis absorption spectra of TAA molecules in water and dichloromethane show maximum absorption at $235 \mathrm{~nm}$ with a molar extinction coefficient as found by the use of Beer-Lambert's law: $\varepsilon_{235}\left(\mathrm{H}_{2} \mathrm{O}\right)=$ $7467 \mathrm{~L} \mathrm{~mol}^{-1} \mathrm{~cm}^{-1}$ and $\varepsilon_{235}\left(\mathrm{CH}_{2} \mathrm{Cl}_{2}\right)=7525 \mathrm{~L} \mathrm{~mol}^{-1} \mathrm{~cm}^{-1}$ (results not shown).

In our previous work concerning gamma induced polymerization of conducting polymers in aqueous solutions, it has been demonstrated that EDOT or Py molecules dissolved in water were oxidized, under $\mathrm{N}_{2} \mathrm{O}$, by $\mathrm{HO}^{\bullet}$ radicals, into PEDOT and PPy conducting polymers. ${ }^{28,30}$ This was possible thanks to 
(a)

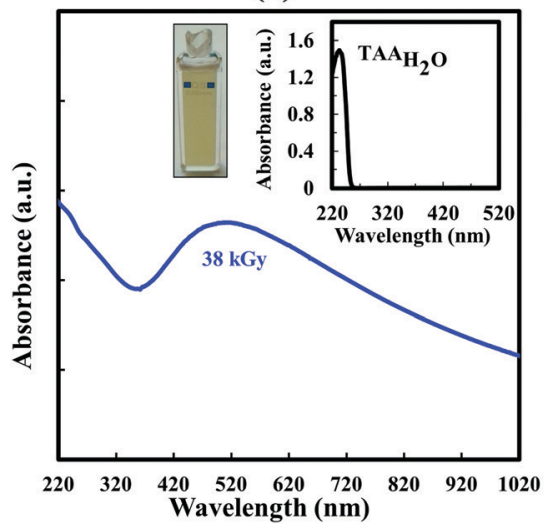

(b)

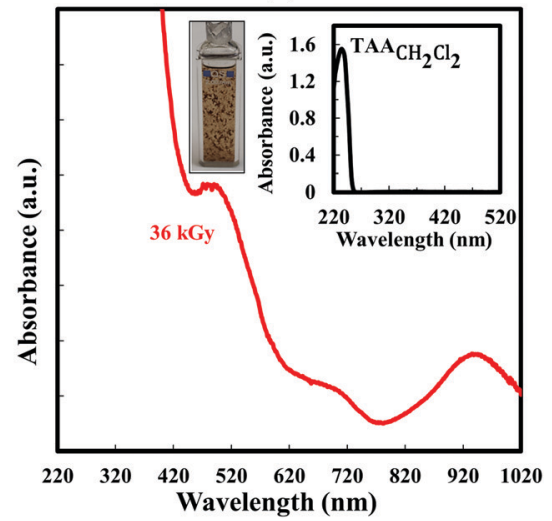

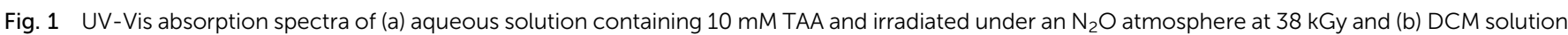

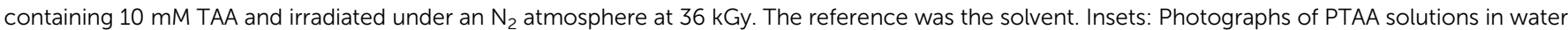

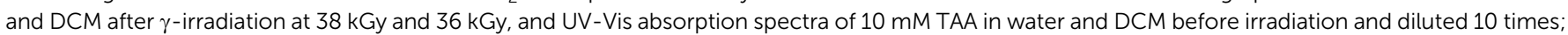
the reference is the pure solvent; $L=0.2 \mathrm{~cm}$.

the relatively high redox potential of $\mathrm{HO}^{\bullet},{ }^{48}$ which is higher than that of EDOT and Py monomers. Under $\mathrm{N}_{2} \mathrm{O}$, the yield of both EDOT and Py oxidation was found to be equal to the radiolytic yield of $\mathrm{HO}^{\bullet}$ formation, which is in agreement with the fact that both PEDOT and PPy polymerizations proceed through a step by step oxidation process. In agreement with these previous studies on PEDOT and PPy, the theoretical irradiation dose $\left(D_{\max }\right)$ that should lead to quantitative formation of PTAA in water under $\mathrm{N}_{2} \mathrm{O}$ can be calculated according to eqn (13).

Aqueous solution containing $10 \mathrm{mM}$ TAA was thus irradiated under $\mathrm{N}_{2} \mathrm{O}$ at this quantitative dose, $D_{\max }=38 \mathrm{kGy}$. The absorption spectrum of the irradiated solution is shown in Fig. 1a. In fact, gamma-irradiation of TAA aqueous solution distinctly leads to the formation of species which absorb at $500 \mathrm{~nm}$. According to the literature, this absorption comes from the $\pi-\pi^{*}$ transitions along the polymer chains and thus can be attributed to the radiation induced formation of PTAA oligomers and polymers. ${ }^{37,54}$ These polymers formed by water radiolysis are called $\mathrm{PTAA}_{\mathrm{H}_{2} \mathrm{O}}$. Note that the observed continuous scattering should result from the presence of a dark yellow suspension in the aqueous medium as observed in the photograph of the solution in the inset of Fig. 1a. As it will be demonstrated later, this suspension corresponds to $\mathrm{PTAA}_{\mathrm{H}_{2} \mathrm{O}}$ polymers which result from the $\mathrm{HO}^{\bullet}$-induced oxidation process. All these findings (the required dose, $D_{\max }$, for complete TAA polymerization, the formation of a suspension and the absorption in the visible) are found to be consistent with the results obtained in our previous work which concerned $\mathrm{HO}^{\bullet}$-induced oxidation of EDOT and $\mathrm{Py}$ monomers. $^{28,30}$

In another study on PEDOT polymers, not in water, but in dichloromethane solvent, ${ }^{31}$ the oxidative polymerization of EDOT has also proceeded but this time under $\mathrm{N}_{2}$. In agreement with this previous study, the theoretical irradiation dose $\left(D_{\max }\right)$ that should lead to quantitative formation of PTAA in dichloromethane under $\mathrm{N}_{2}$ can be calculated according to eqn (3).
Thus, in order to quantitatively produce PTAA polymers, we irradiated dichloromethane solution containing $10 \mathrm{mM}$ TAA under $\mathrm{N}_{2}$ at this optimal dose, $D_{\max }=36 \mathrm{kGy}$, and reported in Fig. $1 \mathrm{~b}$ the UV-Vis absorption spectrum of the resulting solution. The spectrum of the irradiated TAA solution in dichloromethane remarkably shows broad peaks protruding between 490 and $720 \mathrm{~nm}$ and that is concurrent with formation of suspended brownish clumps in dichloromethane solution as observed in the photograph of the solution in the inset of Fig. 1b. As it will be demonstrated later, these absorption peaks and suspension correspond to a PTAA polymer, called PTAA $_{\mathrm{CH}_{2} \mathrm{Cl}_{2}}$, formed at $36 \mathrm{kGy}$ thanks to the oxidizing species produced from $\gamma$-irradiation of dichloromethane solvent. Indeed, PTAA polymers usually display, in solution, characteristic peaks at approximately 400 to $500 \mathrm{~nm}$ which are ascribed to the $\pi-\pi^{*}$ transitions along the polymer chains, ${ }^{37,54}$ while the red shifted absorption band between 550 and $750 \mathrm{~nm}$ can be ascribed to different elongations of the $\mathrm{PTAA}_{\mathrm{CH}_{2} \mathrm{Cl}_{2}}$ delocalized $\pi$-electron chain sequence. Differently, the observed absorption band which grows up at $940 \mathrm{~nm}$ can be attributed to polaron and/or bipolaron bands, which are characteristic of the oxidized state of pre-doped PTAA (with chloride ions, as highlighted later, which result from dichloromethane radiolysis). ${ }^{55}$ These characteristic optical features (absorption in the visible and broad pre-doping bands in the near infrared region) obtained in the case of $\mathrm{PTAA}_{\mathrm{CH}_{2} \mathrm{Cl}_{2}}$ polymers have already been observed in the case of PEDOT polymers produced in dichloromethane. ${ }^{31}$

The dose of about $36 \mathrm{kGy}$ ( $38 \mathrm{kGy}$ in water) is the optimal irradiation dose which enables quantitative polymerization of $10 \mathrm{mM}$ TAA in both corresponding solvents (water and dichloromethane). By looking at the recorded UV-Vis absorption spectra in both solvents, it is clearly seen that the $\mathrm{PTAA}_{\mathrm{H}_{2} \mathrm{O}}$ and PTAA $_{\mathrm{CH}_{2} \mathrm{Cl}_{2}}$ polymers exhibit similar $\lambda_{\max } \approx 500 \mathrm{~nm}$. However, PTAA $\mathrm{CH}_{2} \mathrm{Cl}_{2}$ polymers, unlike $\mathrm{PTAA}_{\mathrm{H}_{2} \mathrm{O}}$ ones, show a red shifted shoulder around $620 \mathrm{~nm}$ and are additionally characterized by the formation of polaron and/or bipolaron 
bands. These bands are characteristic of formation of polymers in an oxidized state. This is due to the considerable amount of hydrochloric acid produced from $\gamma$-irradiation of dichloromethane (see eqn (1)), which yields different doping levels of PTAA $\mathrm{CH}_{2} \mathrm{Cl}_{2}$. As a consequence, the doped PTAA polymers with chloride ions show an absorption maximum at approximately $900 \mathrm{~nm}$ corresponding to the charge carrier band of the charged polymers. ${ }^{18}$

\subsection{Chemical characterization and chain length determination of PTAAs}

The turbid aqueous and dichloromethane solutions obtained after irradiation (38 kGy in water and $36 \mathrm{kGy}$ in dichloromethane) were centrifuged at $13 \mathrm{k} \mathrm{rpm}$ for $15 \mathrm{~min}$ to recuperate the solid parts. The obtained solid powders containing PTAA $_{\mathrm{H}_{2} \mathrm{O}}$ or $\mathrm{PTAA}_{\mathrm{CH}_{2} \mathrm{Cl}_{2}}$ were dried in a laboratory oven at $50{ }^{\circ} \mathrm{C}$ for $24 \mathrm{~h}$ for further characterization (Scheme 2).

Size exclusion chromatography (SEC) was used to determine the number average molecular weight $M_{\mathrm{n}}$ (the statistical average molecular weight of all the PTAA polymer chains) as well as the average molecular weight $M_{\mathrm{w}}$ (which takes into account the molecular weight of a chain in determining contributions to the molecular weight average). For this purpose, solutions of $3 \mathrm{mg} \mathrm{mL}{ }^{-1}$ of $\mathrm{PTAA}_{\mathrm{H}_{2} \mathrm{O}}$ or $\mathrm{PTAA}_{\mathrm{CH}_{2} \mathrm{Cl}_{2}}$ were prepared in THF (inset of Fig. 2). The obtained chromatograms as well as the molecular weights obtained with a polystyrene calibration and calculated from the SEC chromatograms are shown in Fig. 2.

The obtained data from SEC analysis are displayed in the inserted table of Fig. 2. PTAA $\mathrm{H}_{2} \mathrm{O}$ has a number average molecular weight $\left(M_{\mathrm{n}}\right)$ of $1350 \mathrm{~g} \mathrm{~mol}^{-1}$ and weight average molecular weight $\left(M_{\mathrm{w}}\right)$ of $1710 \mathrm{~g} \mathrm{~mol}^{-1}$ with a polydispersity index of 1.26. Also PTAA $\mathrm{CH}_{2} \mathrm{Cl}_{2}$ has a number average molecular weight $\left(M_{\mathrm{n}}\right)$ of $1320 \mathrm{~g} \mathrm{~mol}^{-1}$ and weight average molecular weight $\left(M_{\mathrm{w}}\right)$ of $1860 \mathrm{~g} \mathrm{~mol}^{-1}$ with a polydispersity index of 1.41. For both PTAA $_{\mathrm{H}_{2} \mathrm{O}}$ and $\mathrm{PTAA}_{\mathrm{CH}_{2} \mathrm{Cl}_{2}}$, the measured mean size was found, corresponding to oligomers with several TAA units at around a molar mass of $1800 \mathrm{~g} \mathrm{~mol}^{-1}$. These values show that on average, there are about 13 monomer units in each kind of PTAA polymer chain. Besides, in both cases the polydispersity index is characterized by a reasonable and moderate value. In this regard, SEC's findings highlight no concrete influence of the used solvent on the molecular weight of the synthesized polymers. The convergent molecular weight values, estimated by SEC analysis, are in good agreement with the fact that PTAA $_{\mathrm{H}_{2} \mathrm{O}}$ and $\mathrm{PTAA}_{\mathrm{CH}_{2} \mathrm{Cl}_{2}}$ are characterized by the same maximum absorption at approximately $500 \mathrm{~nm}$.

The molecular weight and the polydispersity index obtained in this work in the case of radiosynthesized PTAA polymers are not far from those obtained by He et al. $\left(M_{\mathrm{w}}=2600 \mathrm{~g} \mathrm{~mol}^{-1}\right.$ with a polydispersity index of 1.59) in the case of PTAA polymers electrochemically prepared. ${ }^{56}$ However, the obtained molecular weight remains far from those of PTAA polymers already prepared by chemical methods $\left(M_{\mathrm{w}}\right.$ between $0.41 \times 10^{4}$ and $\left.1.7 \times 10^{4} \mathrm{~g} \mathrm{~mol}{ }^{-1}\right) \cdot{ }^{37,38,57,58}$ Evidently, such a difference between the obtained molecular weights should result from

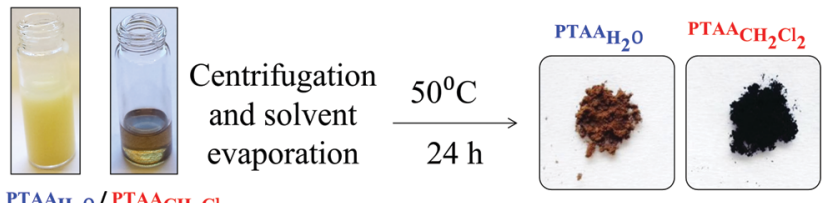

$\operatorname{PTAA}_{\mathrm{H}_{2} \mathrm{O}} / \mathrm{PTAA}_{\mathrm{CH}_{2}} \mathrm{Cl}_{2}$

Scheme 2 The post processing of PTAA polymers after gammairradiation.

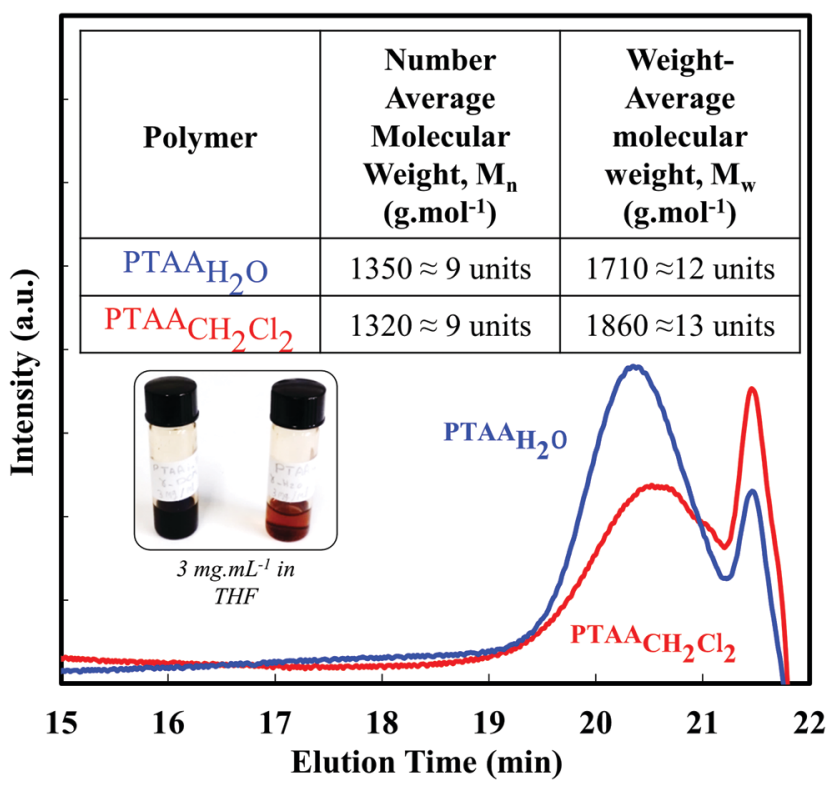

Fig. 2 SEC chromatograms of $3 \mathrm{mg} \mathrm{mL}^{-1}$ of PTAA polymers dissolved in THF solvent. PTAA polymers were synthesized by $\gamma$-induced polymerization in water under $\mathrm{N}_{2} \mathrm{O}$ or in DCM under $\mathrm{N}_{2}$ at irradiation doses of $38 \mathrm{kGy}$ and $36 \mathrm{kGy}$ respectively. The initial concentration of TAA was $10 \mathrm{mM}$. Inset: Photographs of the polymer powders dissolved in THF for SEC experiments.

the quite different (radiolytical, electrochemical and chemical) approaches used for PTAA synthesis.

Attenuated total reflectance-Fourier transform infrared (ATR-FTIR) spectroscopy was used to investigate the chemical nature of the obtained PTAA polymers. ATR-FTIR spectra of PTAA $_{\mathrm{H}_{2} \mathrm{O}}$ and PTAA $\mathrm{CH}_{2} \mathrm{Cl}_{2}$ powders (spectrum b and c) obtained after the drying process are presented in Fig. 3 together with the spectrum of pure non-irradiated TAA powder (spectrum a). Also, Table 1 shows the absorption modes and the positions of the representative peaks of TAA monomers, PTAA $_{\mathrm{H}_{2} \mathrm{O}}$ polymers and $\mathrm{PTAA}_{\mathrm{CH}_{2} \mathrm{Cl}}$ polymers.

Quantitative polymerization was confirmed by the decrease and the disappearance upon irradiation of the $734 \mathrm{~cm}^{-1}$ absorption band (spectrum a), which is attributed to the $=\mathrm{C} \alpha-\mathrm{H}$ out-of-plane deformation vibration of the thiophene ring in TAA monomers. ${ }^{22}$ This peak is remarkable in the monomer spectrum and almost imperceptible in the PTAA polymer spectra. Narrow peaks of low intensity which are observed between 3000 and $2550 \mathrm{~cm}^{-1}$ for both the monomer and the two polymers are attributed to the aliphatic $(\mathrm{C}-\mathrm{H})$ 


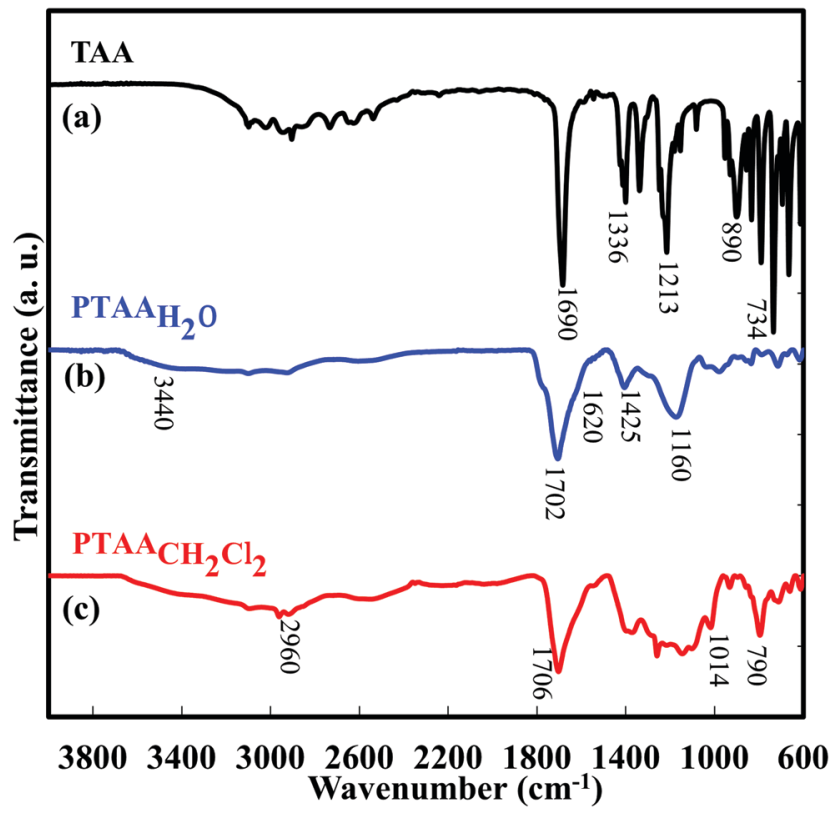

Fig. 3 ATR-FTIR spectra of (a) pure TAA monomers, (b) PTAA $\mathrm{H}_{2} \mathrm{O}$ and (c) PTAA $\mathrm{CH}_{2} \mathrm{Cl}_{2}$. The polymers were synthesized by $\gamma$-induced polymerization in water under $\mathrm{N}_{2} \mathrm{O}$ or in DCM under $\mathrm{N}_{2}$ at irradiation doses of $38 \mathrm{kGy}$ and 36 kGy respectively. The initial concentration was $10 \mathrm{mM}$ TAA.

stretching vibration of aliphatic $\mathrm{C}-\mathrm{H}$ bonds. ${ }^{22}$ The absorption bands between 3200 and $3000 \mathrm{~cm}^{-1}$ are attributed to the stretching vibration of the $(\mathrm{C}-\mathrm{H})$ bond of the thiophene ring. For both PTAA $_{\mathrm{H}_{2} \mathrm{O}}$ and $\mathrm{PTAA}_{\mathrm{CH}_{2} \mathrm{Cl}_{2}}$, in spectra $\mathrm{b}$ and $\mathrm{c}$, the broad band between 3650 and $3100 \mathrm{~cm}^{-1}$ can be assigned to the vibrational modes of $(\mathrm{O}-\mathrm{H})$ groups and indicates the presence of hydrogenbonding interactions. ${ }^{33}$ The $(\mathrm{C}=\mathrm{O})$ stretching vibration at $1690 \mathrm{~cm}^{-1}$ is related to the carboxylic group of the TAA monomer (spectrum a). ${ }^{22}$ This vibration is shifted to $1702 \mathrm{~cm}^{-1}$ for $\mathrm{PTAA}_{\mathrm{H}_{2} \mathrm{O}}$ and to $1706 \mathrm{~cm}^{-1}$ for PTAA $\mathrm{CH}_{2} \mathrm{Cl}_{2}$ (spectra $\mathrm{b}$ and $\mathrm{c}$ ). The presence of a small shoulder at $1750 \mathrm{~cm}^{-1}$ in the case of $\mathrm{PTAA}_{\mathrm{H}_{2} \mathrm{O}}$ (spectrum b) indicates that the carbonyl group is in a less associated state. ${ }^{59}$ It is noteworthy that the $(\mathrm{C}=\mathrm{O})$ stretching vibration of $\mathrm{PTAA}_{\mathrm{CH}_{2} \mathrm{Cl}_{2}}$ exhibits a sharper peak (spectrum c), indicating that the polymer is fully protonated in the case of the organic solvent. ${ }^{60}$ This is ascribed to the presence of $\mathrm{HCl}$ which is generated by the radiolysis of dichloromethane as a stable product.

With further consideration, the absence in the infrared spectrum of $\mathrm{PTAA}_{\mathrm{CH}_{2} \mathrm{Cl}_{2}}$ of the strong band of the $\mathrm{C}-\mathrm{Cl}$ bond between 600 and $700 \mathrm{~cm}^{-1}$ proves that no chlorine atom (produced from dichloromethane radiolysis) is covalently bonded to the backbone of $\mathrm{PTAA}_{\mathrm{CH}_{2} \mathrm{Cl}_{2}}$ polymers. In turn, a shoulder around $1620 \mathrm{~cm}^{-1}$ is observed in spectrum $\mathrm{b}$ of $\mathrm{PTAA}_{\mathrm{H}_{2} \mathrm{O}}$, and should be related to the presence, in this case, of deprotonated carboxylate anions, indicating that the carboxylic groups could partially exist in the deprotonated form within PTAA $_{\mathrm{H}_{2} \mathrm{O}}$ polymers. ${ }^{60}$ The shoulder around $1612 \mathrm{~cm}^{-1}$ and the small peak at $1546 \mathrm{~cm}^{-1}$ in spectrum c of $\mathrm{PTAA}_{\mathrm{CH}_{2} \mathrm{Cl}_{2}}$ can be ascribed to the asymmetrical stretching vibration mode of the quinoid configuration. The absorption at $1336 \mathrm{~cm}^{-1}$ and $1365 \mathrm{~cm}^{-1}$ is assigned to the $(\mathrm{C}-\mathrm{C})$ stretching vibration of the thiophene ring. The bands at 1213, 1160 and $1014 \mathrm{~cm}^{-1}$ are attributed to the $(\mathrm{C}-\mathrm{O})$ bending vibrations belonging to the side chain of the thiophene ring. The bands present at about 933, 790 and $665 \mathrm{~cm}^{-1}$ are attributed to the $\mathrm{C}-\mathrm{S}$ stretching vibration of the ring. ${ }^{59}$ The band at $835 \mathrm{~cm}^{-1}$ is attributed to the $\mathrm{C}_{\beta}-\mathrm{H}$ out-of-plane deformation vibration of the thiophene ring. Finally, as highlighted in the ATR-FTIR spectra, the absorption bands located between 1336 and $1425 \mathrm{~cm}^{-1}$ can be assigned to the inter-ring stretching mode and symmetric stretching vibration mode of $\mathrm{C}-\mathrm{C}$ and $\mathrm{C}=\mathrm{C}$ bonds, respectively. ${ }^{22,38,58}$

As far as one can tell, the slight shifts in the recorded IR spectra of the PTAAs evidently arose from the two distinct hydrophilic aqueous and hydrophobic dichloromethane media. Nevertheless, the two infrared spectra obtained after irradiation reveal the typical bands of PTAA polymers and the careful interpretation of the data asserted the formation of PTAA polymers in both corresponding media.

\subsection{Thermogravimetric analysis (TGA) of PTAAs}

Thermogravimetric analysis (TGA) was used in order to detect and compare the thermo-degradability of the two different radio-synthesized PTAAs. The TGA data for PTAA $_{\mathrm{H}_{2} \mathrm{O}}$ and PTAA $_{\mathrm{CH}_{2} \mathrm{Cl}_{2}}$ are displayed in Fig. 4. In the case of $\mathrm{PTAA}_{\mathrm{H}_{2} \mathrm{O}}$, the TGA curve exhibits about an $8 \%$ initial weight loss observed up to $100{ }^{\circ} \mathrm{C}$, which is probably due to the evaporation of the water molecules which were still adsorbed on the hygroscopic PTAA $_{\mathrm{H}_{2} \mathrm{O}}$ polymer. Differently, $\mathrm{PTAA}_{\mathrm{CH}_{2} \mathrm{Cl}_{2}}$ polymers remain quite stable up to that temperature.

From the PTAA $\mathrm{CH}_{2} \mathrm{Cl}_{2}$ thermogram, it can be clearly observed, above $100{ }^{\circ} \mathrm{C}$, three pronounced falls occurring between $130{ }^{\circ} \mathrm{C}$ and $600{ }^{\circ} \mathrm{C}$. The first process between $130{ }^{\circ} \mathrm{C}$ and $260{ }^{\circ} \mathrm{C}$ corresponds to the degradation of some PTAA oligomers with relatively low molecular weight. The second and third ones,

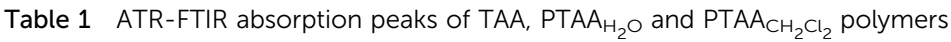

\begin{tabular}{|c|c|}
\hline Functional group & Position $\left(\mathrm{cm}^{-1}\right)$ \\
\hline $\mathrm{C}=\mathrm{C}$ (symmetric stretching mode) & $\approx 1407$ and 1427 \\
\hline $\mathrm{C}=\mathrm{C}$ (asymmetrical stretching vibration mode of the quinoid configuration in the thiophene ring) & $\approx 1614$ and 1546 \\
\hline $\mathrm{C}-\mathrm{C}$ (inter-ring stretching mode) & $\approx 1336$ and 1365 \\
\hline $\mathrm{C}-\mathrm{O}$ (bending vibration) & $\approx 890,1014,1160$ and 1214 \\
\hline $\mathrm{C}-\mathrm{S}-\mathrm{C}$ (stretching vibrations) & $\approx 665,790$ and 933 \\
\hline$=\mathrm{C}_{\alpha}-\mathrm{H}$ (in-plane and out-of-plane deformation vibrations) & $\approx 734$ \\
\hline $\mathrm{C}=\mathrm{O}$ (stretching vibrations) & $\approx 1627$ and 1705 \\
\hline $\mathrm{O}-\mathrm{H}$ stretching vibration mode & $\approx 3100$ to 3600 \\
\hline$=\mathrm{C}_{\beta}-\mathrm{H}$ (out-of-plane deformation vibration) & $\approx 835$ \\
\hline
\end{tabular}




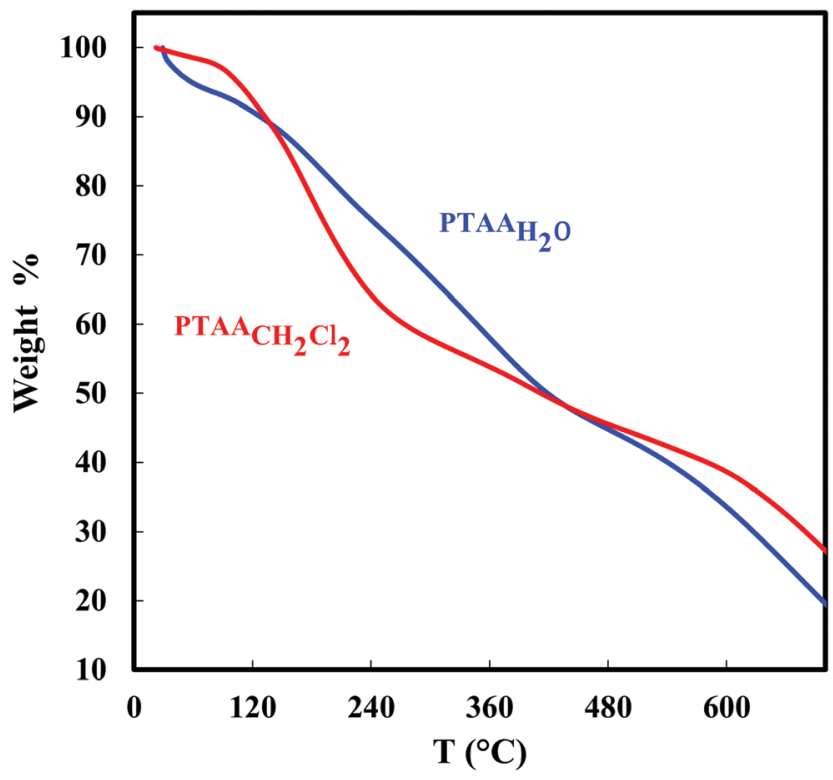

Fig. 4 Thermogravimetric analysis (TGA) graphs of dried $\mathrm{PTAA}_{\mathrm{H}_{2} \mathrm{O}}$

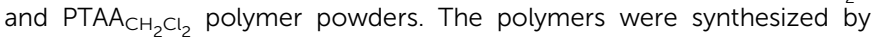
$\gamma$-induced polymerization in water under $\mathrm{N}_{2} \mathrm{O}$ or in DCM under $\mathrm{N}_{2}$ at irradiation doses of $38 \mathrm{kGy}$ and $36 \mathrm{kGy}$ respectively. The initial concentration was $10 \mathrm{mM}$ TAA.

which show up from $260{ }^{\circ} \mathrm{C}$ to $600{ }^{\circ} \mathrm{C}$, correspond to the degradation of $\mathrm{PTAA}_{\mathrm{CH}_{2} \mathrm{Cl}_{2}}$ of higher molecular weight. Finally, above $600{ }^{\circ} \mathrm{C}$, one can observe the progressive decomposition of longer and more stable $\mathrm{PTAA}_{\mathrm{CH}_{2} \mathrm{Cl}_{2}}$ polymers. In regard to $\mathrm{PTAA}_{\mathrm{H}_{2} \mathrm{O}}$, the thermogram curve exhibits, above $130{ }^{\circ} \mathrm{C}$, a continuous weight loss until $20 \%$ of the initial weight of the polymer at $700{ }^{\circ} \mathrm{C}$.

The TGA findings suggest that $\mathrm{PTAA}_{\mathrm{CH}_{2} \mathrm{Cl}_{2}}$ has better thermal stability at the initial stage of weight loss when compared to PTAA $_{\mathrm{H}_{2} \mathrm{O}}$. Also, the TGA analysis of the radio-synthesized PTAAs somehow matches TGA data already reported in the literature concerning PTAAs produced by conventional methodologies. ${ }^{20,54}$ Nevertheless, the relatively substandard behavior of the radiosynthesized PTAA polymers could be due to the relatively low molecular weight.

\subsection{Structural and morphological characterization of radio-synthesized PTAAs}

In order to compare and to check the morphologies of the PTAAs which were produced by the two different radiolysis routes (water and dichloromethane radiolysis), the morphological features of the radio-synthesized PTAAs were scrutinized thanks to several microscopic techniques as displayed in Fig. 5.

3.4.1. Cryo-TEM observations. First and foremost, $\mathrm{PTAA}_{\mathrm{H}_{2} \mathrm{O}}$ and $\mathrm{PTAA}_{\mathrm{CH}_{2} \mathrm{Cl}_{2}}$ were characterized and investigated in solution by cryogenic-transmission electron microscopy (Cryo-TEM). For proper comparison, two solutions at concentration $3 \mathrm{mg} \mathrm{mL}$ were prepared in water and dichloromethane for the corresponding polymers $\mathrm{PTAA}_{\mathrm{H}_{2} \mathrm{O}}$ and $\mathrm{PTAA}_{\mathrm{CH}_{2} \mathrm{Cl}_{2}}$, respectively. The recorded Cryo-TEM images of $\mathrm{PTAA}_{\mathrm{H}_{2} \mathrm{O}}$ and $\mathrm{PTAA}_{\mathrm{CH}_{2} \mathrm{Cl}_{2}}$ are presented in Fig. 5a and $\mathrm{b}$, respectively. Thanks to sample freezing, this technique enables in situ observation, in water (a)

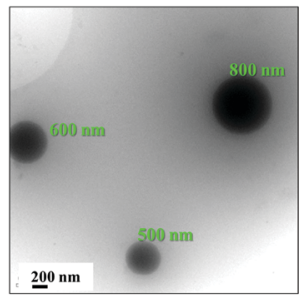

(c)

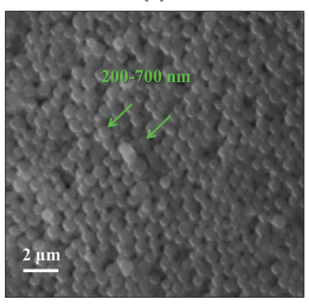

(e)

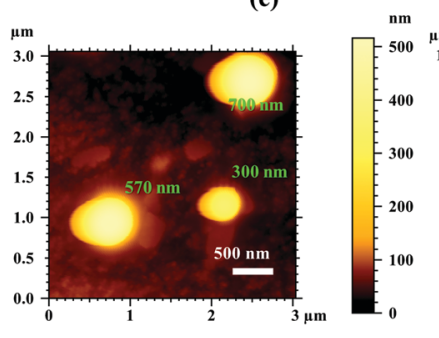

(b)

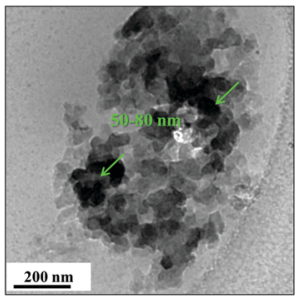

(d)

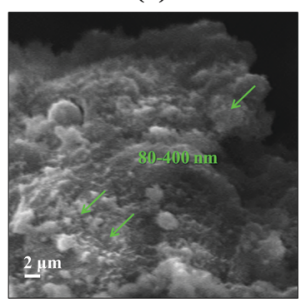

(f)
Fig. 5 Morphological characterization of radio-synthesized PTAAs: (a) Cryo-TEM images of $\mathrm{PTAA}_{\mathrm{H}_{2} \mathrm{O}}$ polymers self-assembled in water, (b) Cryo-TEM image of PTAA $\mathrm{CH}_{2} \mathrm{Cl}_{2}$ polymers self-assembled in dichloromethane solvent, ( $\mathrm{C}$ and d) SEM images of dried PTAA $\mathrm{H}_{2} \mathrm{O}$ and PTAA $\mathrm{CH}_{2} \mathrm{Cl}_{2}$ polymer powder after deposition onto carbon tape adhered to aluminum mounts and gold coating, and (e and f) AFM topographic images of PTAA $_{\mathrm{H}_{2} \mathrm{O}}$ and PTAA $\mathrm{CH}_{2} \mathrm{Cl}_{2}$ polymers after deposition onto the $\mathrm{CaF}_{2}$ disk. The AFM was used in tapping mode. The polymers were synthesized by $\gamma$-induced polymerization in water under $\mathrm{N}_{2} \mathrm{O}$ or in DCM under $\mathrm{N}_{2}$ at irradiation doses of $38 \mathrm{kGy}$ and $36 \mathrm{kGy}$ respectively. The initial concentration was $10 \mathrm{mM}$ TAA.

and dichloromethane, of radiosynthesized polymers, avoiding any phase transition and any aggregation which could result from drying procedures.

The representative Cryo-TEM image of PTAA $_{\mathrm{H}_{2} \mathrm{O}}$ shows the presence of low-density globular structures forming polydisperse spherical nanoparticles with a diameter between 300 and $800 \mathrm{~nm}$ as observed in Fig. 5a. Given that no other low-density objects were observed during our Cryo-TEM experiments, we deduce that these spherical nanoparticles are made up of $\mathrm{PTAA}_{\mathrm{H}_{2} \mathrm{O}}$ polymer chains interacting into each spherical nanoparticle by intermolecular $\mathrm{H}$-bonds (thanks to $-\mathrm{COOH}$ groups). These observations are consistent with our previous results concerning the hydroxyl-induced radio-synthesis of PEDOT polymers in aqueous solutions. ${ }^{26}$

On the other hand, Fig. 5b displays a zoom of one of the circular holes of the holey-carbon grid loaded with $\mathrm{PTAA}_{\mathrm{CH}_{2} \mathrm{Cl}_{2}}$ frozen film. A granular cluster of $1.2 \mu \mathrm{m}$ in size is observed in this case, and is composed of granular self-assembled nanoparticles with diameters between 50 and $80 \mathrm{~nm}$. Such granular clusters were observed in the whole sample indicating that 
PTAA $_{\mathrm{CH}_{2} \mathrm{Cl}_{2}}$ nanoparticles are aggregated in dichloromethane and not isolated as in the case of water. This would imply the existence in dichloromethane of additional interparticle interactions between the polymer chains (in addition to the intraparticle ones). Indeed, these $\mathrm{H}$-bond interactions between two polymer chains located in two distinct PTAA nanoparticles should be strong enough in dichloromethane (leading to self-assembled PTAA $\mathrm{CH}_{2} \mathrm{Cl}_{2}$ nanoparticles), while they are totally screened in a protic solvent, such as water, leading to independent spherical PTAA $\mathrm{H}_{2} \mathrm{O}$ nanoparticles.

3.4.2. XRD analysis. To carry out this analysis, the samples were dried in laboratory oven at $50{ }^{\circ} \mathrm{C}$ for $24 \mathrm{~h}$ after a centrifugation procedure for further characterization by using $\mathrm{X}$-ray diffraction. The aim was to analyze the structure and to check the crystallinity of $\mathrm{PTAA}_{\mathrm{H}_{2} \mathrm{O}}$ and $\mathrm{PTAA}_{\mathrm{CH}_{2} \mathrm{Cl}_{2}}$ synthesized by gamma-radiolysis of water and DCM. The typical XRD patterns are exhibited in Fig. 6 .

The diffraction peaks at about $38^{\circ}, 44^{\circ}, 64^{\circ}$ and $78^{\circ}$ originated from the aluminum support used in this work. As can be seen in the XRD diffractograms, both XRD patterns are closely identical and no particular feature form of both PTAA polymers is detected, as they are probably amorphous polymers. The amorphous nature of the PTAAs is highlighted and confirmed from the broad diffraction peak at $2 \theta \sim 21.5^{\circ}$, which corresponds to the interlayer stacking chain-to-chain distance. ${ }^{31}$ Both PTAA diffractograms closely match those earlier reported in the literature in the case of chemically synthesized PTAA polymers. ${ }^{23,61}$

3.4.3. SEM observations. In the solid state after the deposition procedure and the drying steps, SEM was used. SEM images were

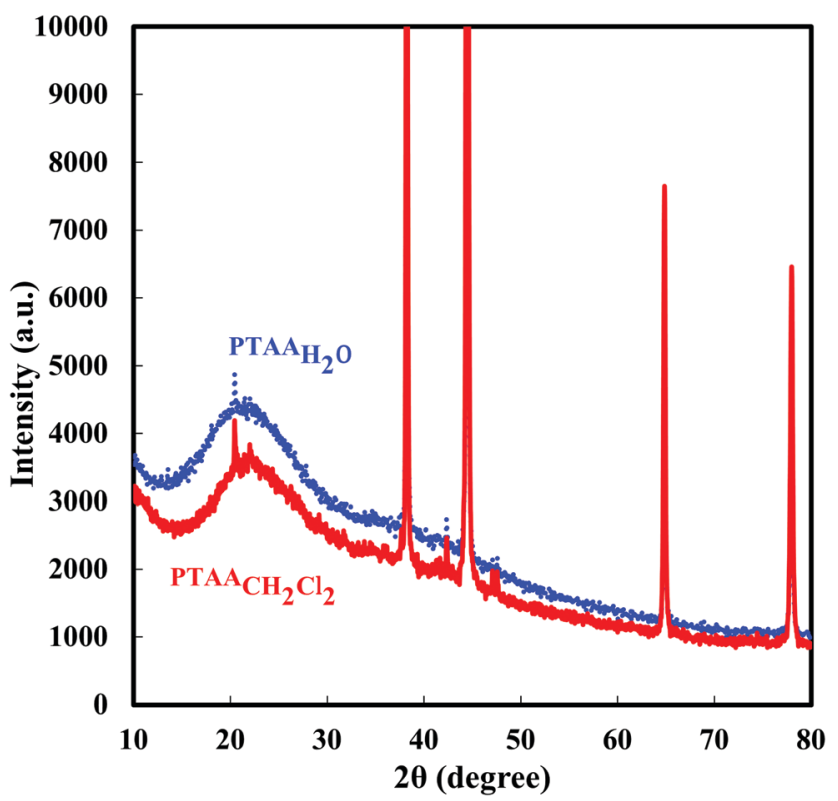

Fig. 6 XRD diffractograms of dried $P T A A_{H_{2}} \mathrm{O}$ and $P T A A_{C_{2}} C_{2}$ polymer powders. The polymers were synthesized by $\gamma$-induced polymerization in water under $\mathrm{N}_{2} \mathrm{O}$ or in DCM under $\mathrm{N}_{2}$ at irradiation doses of $38 \mathrm{kGy}$ and 36 kGy respectively. The initial concentration was $10 \mathrm{mM}$ TAA. The substrate used for XRD analysis was aluminum. recorded after deposition of the dried $\mathrm{PTAA}_{\mathrm{H}_{2} \mathrm{O}}$ and $\mathrm{PTAA}_{\mathrm{CH}_{2} \mathrm{Cl}_{2}}$ polymer powders onto carbon tape adhered to aluminum mounts and gold coating. Some of these images are displayed in Fig. 5. Note that without the gold coating, similar images have been obtained but with lower resolution. In Fig. 5c the SEM image of $\mathrm{PTAA}_{\mathrm{H}_{2} \mathrm{O}}$ is presented. The image shows close-packed spherule beads with a size range between 200 and $700 \mathrm{~nm}$. These SEM observations agree well with the morphology of PTAAs previously observed before deposition by Cryo-TEM (Fig. 5a) without any significant change neither in the mean size nor in the shape. Also, the packing of the particles and their flattening onto the substrate when deposited and dried do not seem to affect the nanostructuration of $\mathrm{PTAA}_{\mathrm{H}_{2} \mathrm{O}}$ polymers.

A representative SEM image of $\mathrm{PTAA}_{\mathrm{CH}_{2} \mathrm{Cl}_{2}}$ is shown in Fig. 5d. $\mathrm{PTAA}_{\mathrm{CH}_{2} \mathrm{Cl}_{2}}$ appears outwardly as a large aggregation of several micrometers. However, by looking very closely, it is possible to recognize tightly close-packed granular nanoparticles of several hundreds of nanometers. The particles observed by SEM after deposition are of the same size or slightly bigger than the globular nanostructures observed by Cryo-TEM in dichloromethane solution before deposition (Fig. 5b). The aggregation of the particles upon the drying procedure, due to the phase transition, which is facilitated in this case by the pre-existence of interparticle interactions in dichloromethane, should explain the packing and the polydispersity in size observed in Fig. 5d.

3.4.4. EDX spectroscopy. During SEM observations and without gold coating, in situ energy-dispersive X-ray spectroscopy (EDX) was carried out in order to identify the chemical composition of the materials and to perform elemental analysis on different areas of the deposited nanoparticles. EDX highlighted the presence of sulfur (in addition to carbon and oxygen) in the whole PTAA $\mathrm{CH}_{2} \mathrm{Cl}_{2}$ and PTAA $\mathrm{H}_{2} \mathrm{O}$ samples, demonstrating that our materials are effectively made of PTAA polymers. Particularly, EDX enabled the detection of chlorine atoms dispersed in $\mathrm{PTAA}_{\mathrm{CH}_{2} \mathrm{Cl}_{2}}$ granular nanoparticles, while these atoms were evidently totally absent from the PTAA $_{\mathrm{H}_{2} \mathrm{O}}$ sample. This observation definitely demonstrates that radiosynthesized PTAA $\mathrm{CH}_{2} \mathrm{Cl}_{2}$ polymers are doped with chloride ions, in total agreement with our results obtained by UV-Vis absorption spectrophotometry and by ATR-FTIR spectroscopy.

3.4.5. AFM observations. AFM microscopy was used to get better morphological analysis for $\mathrm{PTAA}_{\mathrm{CH}_{2} \mathrm{Cl}_{2}}$ and $\mathrm{PTAA}_{\mathrm{H}_{2} \mathrm{O}}$ powders obtained after $\gamma$-irradiation at the optimal dose (36 kGy in dichloromethane and $38 \mathrm{kGy}$ in water). First, PTAA $_{\mathrm{CH}_{2} \mathrm{Cl}_{2}}$ and PTAA $\mathrm{H}_{2} \mathrm{O}$ powders were dissolved in ethanol $\left(1.5 \mathrm{mg} \mathrm{mL}^{-1}\right)$ and then a small drop of each ethanolic solution was deposited onto the upper surface of a ZnSe prism and dried naturally in air. Each of the obtained films was then scanned by AFM (Fig. 5). According to the AFM images of the samples recorded in tapping mode (Fig. 5e and f), the bottom dark areas having no thickness correspond to the substrate, while the bright areas correspond to the topography of the samples.

In Fig. 5e the AFM topography of $\mathrm{PTAA}_{\mathrm{H}_{2} \mathrm{O}}$ is presented. Distinctly, the topography of $\mathrm{PTAA}_{\mathrm{H}_{2} \mathrm{O}}$ displayed as the bright areas corresponds to the thicker regions made up of nano-spherules 
with sizes in the range between $300 \mathrm{~nm}$ and $700 \mathrm{~nm}$. The AFM topography of $\mathrm{PTAA}_{\mathrm{CH}_{2} \mathrm{Cl}_{2}}$ presented in Fig. 5f shows markedly small granular nanoparticles of several tens of nanometers as well as aggregated granular clusters of $800 \mathrm{~nm}$ to $1200 \mathrm{~nm}$. The observed aggregated clusters are evidently ascribed to the fact that dichloromethane is not a good solvent of $\mathrm{PTAA}_{\mathrm{CH}_{2} \mathrm{Cl}_{2}}$ nanoparticles. Subsequently $\mathrm{PTAA}_{\mathrm{CH}_{2} \mathrm{Cl}_{2}}$ nano-granules get together to form large aggregations.

Importantly, one can note that the shape, the size and the morphology of PTAA $_{\mathrm{CH}_{2} \mathrm{Cl}_{2}}$ nano-granules and PTAA $_{\mathrm{H}_{2} \mathrm{O}}$ nanospherules observed here by AFM microscopy are in total agreement with the previous observations made by SEM and CryoTEM. According to the microscopic observations (Cryo-TEM, SEM and AFM), $\gamma$-radiation induced polymerization of TAA, conducted either in dichloromethane or in aqueous solutions, successfully leads to two different polymer nanostructures. These dissimilarities indeed arose from the influence of the polarity, proticity and dissociating power of the two solvents. In addition, as highlighted by EDX, $\mathrm{PTAA}_{\mathrm{CH}_{2} \mathrm{Cl}_{2}}$ is found to be doped by chlorine atoms. As a consequence of different polymeric morphologies and nanostructures as well as different doping states, the radio-synthesized $\mathrm{PTAA}_{\mathrm{CH}_{2} \mathrm{Cl}_{2}}$ and $\mathrm{PTAA}_{\mathrm{H}_{2} \mathrm{O}}$ effectively possess distinct optical properties as already found and described (see Fig. 1).

\subsection{Electronic and electrochemical properties of radio- synthesized PTAAs}

PTAA $_{\mathrm{CH}_{2} \mathrm{Cl}_{2}}$ and PTAA $_{\mathrm{H}_{2} \mathrm{O}}$ powders obtained after $\gamma$-irradiation and solvent evaporation were dissolved in DCM at a concentration of $10 \mathrm{mg} \mathrm{mL}^{-1}$. Then, $100 \mu \mathrm{L}$ of the solution was spincoated on a clean glass substrate and the obtained films were doped with $\mathrm{NOBF}_{4}(20 \mathrm{mM})$ in acetonitrile. After measuring the thickness of the films by a surface profiler, their conductivities were determined by the four-point probe technique (Table 2).

Table 2 shows the determined electrical conductivities together with the calculated electronic band gaps and optical band gaps (which will be discussed later) of the PTAA polymers. The average electrical conductivities of $\mathrm{PTAA}_{\mathrm{H}_{2} \mathrm{O}}$ and $\mathrm{PTAA}_{\mathrm{CH}_{2} \mathrm{Cl}_{2}}$ as measured by the four-point probe technique were found to be $0.6 \times 10^{-3} \mathrm{~S} \mathrm{~cm}^{-1}$ and $1.6 \times 10^{-3} \mathrm{~S} \mathrm{~cm}^{-1}$, respectively. Remarkably, $\mathrm{PTAA}_{\mathrm{CH}_{2} \mathrm{Cl}_{2}}$ has an electrical conductivity which is roughly 3 times higher than that of $\mathrm{PTAA}_{\mathrm{H}_{2} \mathrm{O}}$. That should result from the difference in the morphology and the doping state of the PTAA polymers. It is worth noting that the amount of

Table 2 Conductivities of PTAA polymers measured by using the fourpoint probe technique after doping with $20 \mathrm{mM} \mathrm{NOBF}_{4}$, electronic band gaps calculated from cyclic voltammetry measurements and optical band gaps, $E_{\text {gap }}$, extrapolated from Tauc plots for the PTAA polymers. The PTAA polymers were synthesized by gamma-induced polymerization in water under $\mathrm{N}_{2} \mathrm{O}$ or in DCM under $\mathrm{N}_{2}$ at irradiation doses of $38 \mathrm{kGy}$ and $36 \mathrm{kGy}$ respectively. The initial concentration of TAA was $10 \mathrm{mM}$

\begin{tabular}{llll}
\hline Polymer & $\begin{array}{l}\text { Electrical conductivity } \\
\times 10^{-3}\left(\mathrm{~S} \mathrm{~cm}^{-1}\right)\end{array}$ & $\begin{array}{l}\text { Electronic } \\
\text { band gap (eV) }\end{array}$ & $\begin{array}{l}\text { Optical } \\
\text { band gap (eV) }\end{array}$ \\
\hline PTAA $_{\mathrm{H}_{2} \mathrm{O}}$ & 0.60 & 2.59 & 2.37 \\
PTAA $_{\mathrm{CH}_{2} \mathrm{Cl}_{2}}$ & 1.60 & 2.46 & 2.00
\end{tabular}

hydrochloric acid produced from $\gamma$-irradiation of dichloromethane yields to doping of $\mathrm{PTAA}_{\mathrm{CH}_{2} \mathrm{Cl}_{2}}$, while $\mathrm{PTAA}_{\mathrm{H}_{2} \mathrm{O}}$ remains undoped. Note that the electrical conductivity measurements made for radiosynthesized $\mathrm{PTAA}_{\mathrm{H}_{2} \mathrm{O}}$ and $\mathrm{PTAA}_{\mathrm{CH}_{2} \mathrm{Cl}_{2}}$ show relatively higher conductivities in comparison with those already reported in the literature for PTAA polymers produced by conventional synthetic methods. ${ }^{20,24,54}$

The electronic properties of $\mathrm{PTAA}_{\mathrm{H}_{2} \mathrm{O}}$ and $\mathrm{PTAA}_{\mathrm{CH}_{2} \mathrm{Cl}_{2}}$ were investigated in order to inspect their potential applications. The oxidation and reduction potentials of $\mathrm{PTAA}_{\mathrm{H}_{2} \mathrm{O}}$ and $\mathrm{PTAA}_{\mathrm{CH}_{2} \mathrm{Cl}_{2}}$ were therefore monitored under similar experimental conditions by using cyclic voltammetry (CV) analysis (Fig. 7). For this purpose, solutions of $3 \mathrm{mg} \mathrm{mL}{ }^{-1}$ of $\mathrm{PTAA}_{\mathrm{H}_{2} \mathrm{O}}$ and PTAA $\mathrm{CH}_{2} \mathrm{Cl}_{2}$ were prepared in THF. $1 \mathrm{~mL}$ of this solution was mixed with $5 \mathrm{~mL}$ of acetonitrile solution containing tetrabutylammonium hexafluorophosphate $\left(\mathrm{TBAPF}_{6}\right)$ used as an electrolyte at a concentration of $0.1 \mathrm{M}$.

The CV profiles show that the main p-doping (oxidation) process occurs at onset potentials of $+1.84 \mathrm{~V}\left(\mathrm{PTAA}_{\mathrm{H}_{2} \mathrm{O}}\right)$ and $+1.75 \mathrm{~V}\left(\mathrm{PTAA}_{\mathrm{CH}_{2} \mathrm{Cl}_{2}}\right)$, while n-doping starts at $-0.75 \mathrm{~V}\left(\mathrm{PTAA}_{\mathrm{H}_{2} \mathrm{O}}\right)$

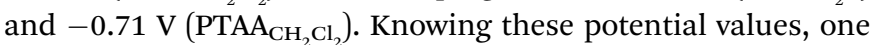
can calculate, from the equation given in the legend of Fig. 7, the $\mathrm{HOMO} / \mathrm{LUMO}$ energy levels of radiosynthesized $\mathrm{PTAA}_{\mathrm{H}_{2} \mathrm{O}}$ and $\mathrm{PTAA}_{\mathrm{CH}_{2} \mathrm{Cl}_{2}}$. Both the energy level of the highest occupied molecular orbital (HOMO) and the energy level of the lowest unoccupied molecular orbital (LUMO) were calculated, from the ionization potential and the electronic affinity, respectively. $E_{\mathrm{HOMO}}$ and $E_{\mathrm{LUMO}}$ amount respectively to $-6.24 \mathrm{eV}$ and $-3.65 \mathrm{eV}\left(\mathrm{PTAA}_{\mathrm{H}_{2} \mathrm{O}}\right)$ and $-6.15 \mathrm{eV}$ and $-3.69 \mathrm{eV}\left(\mathrm{PTAA}_{\mathrm{CH}_{2} \mathrm{Cl}_{2}}\right)$, leading to an electrochemical band gap of $2.59 \mathrm{eV}\left(\mathrm{PTAA}_{\mathrm{H}_{2} \mathrm{O}}\right)$ and $2.46 \mathrm{eV}\left(\mathrm{PTAA}_{\mathrm{CH}_{2} \mathrm{Cl}_{2}}\right)$, as shown in Table 2. The HOMO/ LUMO energy levels of the materials were calculated by using the ferrocene ionization potential value as a standard. The corrected value of $4.8 \mathrm{eV} v s$. vacuum of ferrocene is widely adopted. The value is based on the calculation obtained by Pommerehne et al. ${ }^{62}$

It is fairly obvious that the oxidation and reduction onsets of PTAA $_{\mathrm{H}_{2} \mathrm{O}}$ and $\mathrm{PTAA}_{\mathrm{CH}_{2} \mathrm{Cl}_{2}}$ provide matching values. The cyclic voltammetry findings and the comparable electrochemical band gaps of both radiosynthesized PTAAs suggest that both polymers have the same electronic behavior and indeed the results are consistent with the SEC data since the two $\mathrm{PTAA}_{\mathrm{H}_{2} \mathrm{O}}$ and $\mathrm{PTAA}_{\mathrm{CH}_{2} \mathrm{Cl}_{2}}$ polymers roughly possess the same molecular weight and thus comparable electronic band gaps. Anyhow, the calculated electronic band gaps found in this radiolytic work are closely matching results earlier reported in the literature for PTAA polymers chemically synthesized by $\mathrm{FeCl}_{3} \cdot{ }^{58,63}$

On the other hand, the optical band gap measurement in the field of conducting polymers (CPs) is also important for some applications such as CP-based solar cell devices and therefore the cyclic voltammetry results were upheld by drawing on Tauc plots for $\mathrm{PTAA}_{\mathrm{H}_{2} \mathrm{O}}$ and PTAA $\mathrm{CH}_{2} \mathrm{Cl}_{2}$ polymers. The two Tauc plots were read out from the recorded absorption spectra of $\mathrm{PTAA}_{\mathrm{H}_{2} \mathrm{O}}$ and $\mathrm{PTAA}_{\mathrm{CH}_{2} \mathrm{Cl}_{2}}$ dissolved in THF, as depicted in the inset of Fig. 8a and b. The UV-Vis absorption spectrum of PTAA $_{\mathrm{H}_{2} \mathrm{O}}$ in THF (Fig. 8a) does not retain the same spectral features as those observed in the spectrum of Fig. 1a 

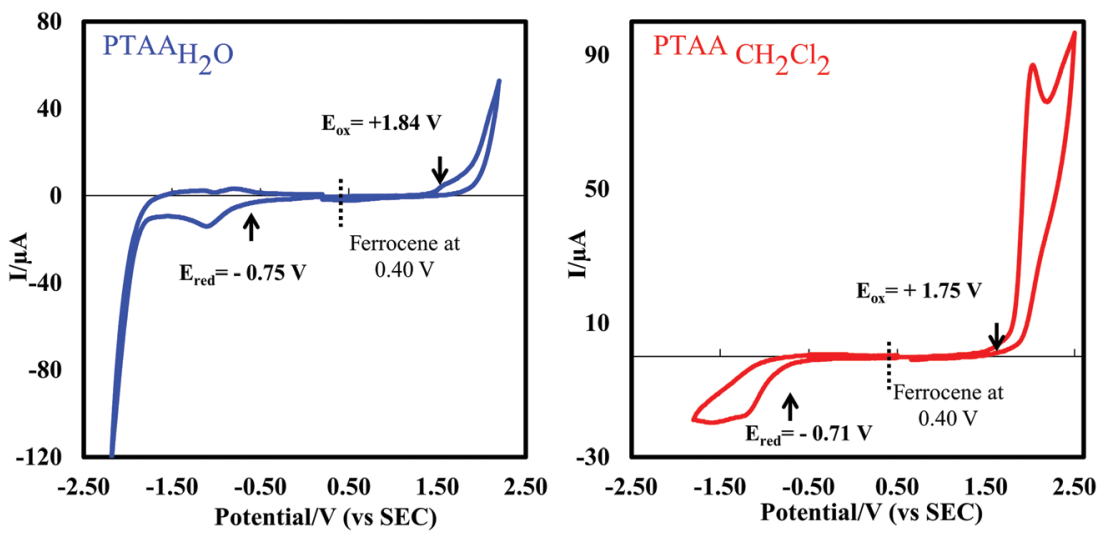

Fig. 7 Cyclic voltammograms of $3 \mathrm{mg} \mathrm{L}^{-1}$ of $\mathrm{PTAA}_{\mathrm{H}_{2} \mathrm{O}}$ and PTAA $\mathrm{CH}_{2} \mathrm{Cl}_{2}$ dissolved in THF and recorded in acetonitrile containing $0.1 \mathrm{M}$ of TBAPF 6 at a scan rate of $100 \mathrm{mV} \mathrm{s}^{-1}$. The polymers were synthesized by induced polymerization in water under $\mathrm{N}_{2} \mathrm{O}$ or in DCM under $\mathrm{N}_{2}$ at irradiation doses of $38 \mathrm{kGy}$ and $36 \mathrm{kGy}$ respectively. The initial concentration was $10 \mathrm{mM}$ TAA. The ferrocenium/ferrocene $\left(\mathrm{Fc}^{+} / \mathrm{Fc}\right)$ redox potential was measured in order to calibrate the pseudo-reference electrode ( $0.4 \mathrm{~V}$ vs. SEC in the present study). The HOMO/LUMO energetic levels of PTAAs were calculated as follows: $E_{\mathrm{HOMO}}$ (eV) from ionization potential $=-4.80-e\left(E_{\mathrm{Ox}}-0.40\right)$ and $E_{\mathrm{LUMO}}(\mathrm{eV})$ from electronic affinity $=-4.80-e\left(E_{\mathrm{red}}-0.40\right)$ where $e$ is the elementary charge.

(a)

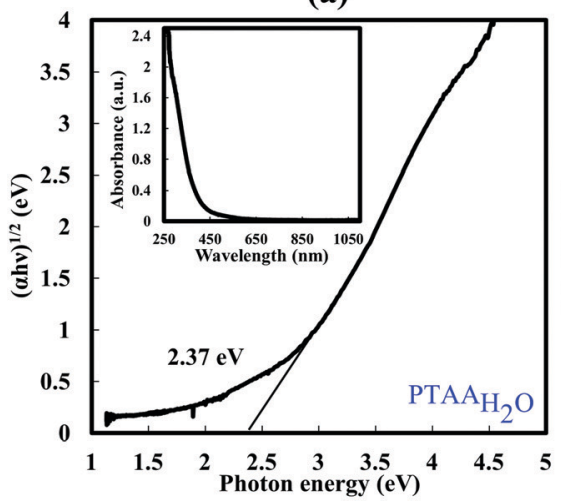

(b)

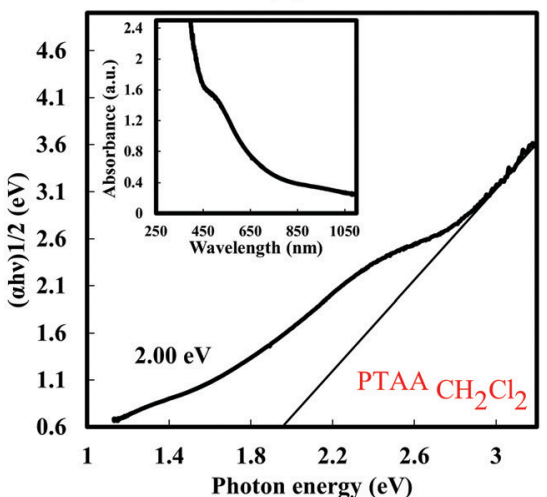

Fig. 8 Tauc plot analysis of UV-Vis absorption spectra of $\mathrm{PTAA}_{\mathrm{H}_{2} \mathrm{O}}$ and $\mathrm{PTAA}_{\mathrm{CH}_{2} \mathrm{Cl}_{2}}$ in THF solvent for optical band gap assessment indicating the indirect

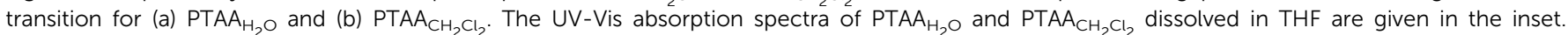
The reference is THF. $L=0.2 \mathrm{~cm}$.

which was recorded in water. On the contrary, it is possible to discern that the absorption spectrum of $\mathrm{PTAA}_{\mathrm{CH}_{2} \mathrm{Cl}_{2}}$ in THF (Fig. 8b) retains the same absorption peaks as those observed in Fig. $1 \mathrm{~b}$, especially, the one attributed to doping effect.

In the context of the Tauc plot, based on Tauc's equation presented below, $(\alpha h \nu)^{1 / n}$ is principally plotted as a function of photon energy $(h \nu):^{64}$

$$
(\alpha h \nu)^{1 / n}=A\left(h \nu-E_{\text {gap }}\right)
$$

where $\alpha, h, \nu$ and $E_{\text {gap }}$ are respectively the absorption coefficient, Planck constant, light frequency, and optical band gap energy and $A$ is a constant. The exponent $n$ is 0.5 for direct allowed transitions, 1.5 for direct forbidden transitions, 2 for indirect allowed transitions and 3 for indirect forbidden transitions. ${ }^{64,65}$ Here, the value of $n$ should be $n=2$, due to the amorphous nature of the two polymers, which indicates allowed indirect transitions.

As a consequence, in our case, if $n=2$ :

$$
(\alpha h \nu)^{1 / 2}=A\left(h \nu-E_{\text {gap }}\right)
$$

Thus, optical band gaps $E_{\text {gap }}$ can be calculated from the linear relation of $(\alpha h \nu)^{1 / 2}$ as a function of $h \nu$ (photon energy) and can be determined by linear fit extrapolations to the $x$-axis of the plots.

As observed in Fig. 8, plotting $(\alpha h \nu)^{1 / 2}$ versus photon energy enabled us to get optical band gap energies, $E_{\text {gap }}$, for the $\mathrm{PTAA}_{\mathrm{H}_{2} \mathrm{O}}$ (Fig. 8a) and $\mathrm{PTAA}_{\mathrm{CH}_{2} \mathrm{Cl}_{2}}$ (Fig. 8b) polymers by the intercept of the two tangents with the $x$-axis. The optical band gap energies of the $\mathrm{PTAA}_{\mathrm{H}_{2} \mathrm{O}}$ and $\mathrm{PTAA}_{\mathrm{CH}_{2} \mathrm{Cl}_{2}}$ polymers were estimated to be $2.37 \mathrm{eV}$ and $2.00 \mathrm{eV}$, respectively, as shown in Table 2. Note that these band gap values are very close to the value $(2.40 \mathrm{eV})$ given by Hironori et al. in the case of PTAA polymers prepared by electrochemistry. ${ }^{66}$

We can observe in Table 2 that the optical band gap values (2.37 and $2.00 \mathrm{eV}$ ) are smaller than the electrochemical ones (2.59 and $2.48 \mathrm{eV}$ respectively) for both PTAA polymers. Indeed, usually, the electronic band gaps are larger than the optical ones since the measurements by electrochemistry require additional energy because of Coulomb interactions. 
One can note that the obtained $E_{\text {gap }}$ for PTAA $\mathrm{CH}_{2} \mathrm{Cl}_{2}$ exhibits a considerable difference of 0.37 , in comparison with that of PTAA $\mathrm{H}_{2} \mathrm{O}$. Here again, the pre-doping of $\mathrm{PTAA}_{\mathrm{CH}_{2} \mathrm{Cl}_{2}}$ with chloride ions resulting from dichloromethane radiolysis should afford, as expected, a lower optical band gap of PTAA $_{\mathrm{H}_{2} \mathrm{O}}$. More importantly, we can optimistically claim that our two radiosynthesized materials ( $\mathrm{PTAA}_{\mathrm{H}_{2} \mathrm{O}}$ and $\mathrm{PTAA}_{\mathrm{CH}_{2} \mathrm{Cl}_{2}}$ ) can potentially be used in different applications, such as in solar cells, due to their appropriate (low) and pertinent (in the field) $E_{\text {gap }}$ values.

\section{Conclusion}

Current research aims to develop new synthesis strategies and new conducting polymers with tuned morphologies and properties. We recently, and for the first time in the literature, used $\gamma$-radiolysis as an original simple alternative way for synthesizing nanostructured conducting PPy and PEDOT polymers in aqueous solution. In order to overcome their low solubility issue, we very recently extended our strategy based on radiation chemistry to the preparation of PEDOT conducting polymers in organic solvents.

In order to carry forward the development of our methodology, to control the optical properties of radio-synthesized materials and to tune the polymer morphology, we decided, in the present work, to extend our radiolytic method to the synthesis of one of the most important polythiophene derivatives, namely PTAA, knowing that its synthesis by conventional methods presents many issues.

We exhibit, in the present manuscript, two original and simple radiolytic routes based on radiation induced oxidation of TAA, for production of PTAA polymers either in aqueous solution or in dichloromethane solvent. Starting from TAA monomers dissolved in water or in dichloromethane, the oxidative polymerization of TAA was induced by gamma irradiation at doses of 38 and $36 \mathrm{kGy}$, respectively. Successfully, depending on the solvent, two different kinds of PTAA polymers (called $\mathrm{PTAA}_{\mathrm{H}_{2} \mathrm{O}}$ and PTAA $\mathrm{CH}_{2} \mathrm{Cl}_{2}$ ) were prepared. Spectroscopic analysis represented by UV-Vis and ATR-FTIR spectroscopies manifested distinct chemical and optical properties for both polymers. In particular, $\mathrm{PTAA}_{\mathrm{CH}_{2} \mathrm{Cl}_{2}}$ polymers were found to be doped with chloride ions produced by dichloromethane radiolysis as confirmed by EDX spectroscopy.

SEC analysis showed that the nature of the solvent has no influence on the molecular weight of the radio-synthesized polymers. Both polymers were found to be amorphous as highlighted by XRD. TGA analysis demonstrated good and convergent thermal stabilities. Morphological characterizations of both PTAA $\mathrm{H}_{2} \mathrm{O}$ and $\mathrm{PTAA}_{\mathrm{CH}_{2} \mathrm{Cl}_{2}}$ were carried out either in solution by cryo-TEM or after deposition onto substrates by SEM and AFM. All microscopic observations revealed that $\gamma$-synthesized PTAAs have two different morphologies: PTAA $\mathrm{CH}_{2} \mathrm{Cl}_{2}$ polymer chains self-assemble into aggregated granular nanostructures of several tens of nanometers, whereas PTAA $_{\mathrm{H}_{2} \mathrm{O}}$ polymer chains form spherical nanoparticles of a few hundred nanometer size.
The cyclic voltammetry analysis and optical band gap calculations for both PTAA polymers were favorable for any practical application. Also, the electrical conductivity results are quite remarkable and even better than the electrical properties that have already been reported in the literature for PTAA polymers synthesized by conventional methods, highlighting the success of our original radiation based methodology and demonstrating that our radio-synthesized polymers constitute promising candidates and usable polymers for different practical applications. Note that, due to doping of $\mathrm{PTAA}_{\mathrm{CH}_{2} \mathrm{Cl}_{2}}$ with chloride ions, the optical and electrical features of $\mathrm{PTAA}_{\mathrm{CH}_{2} \mathrm{Cl}_{2}}$ outperform those of PTAA $\mathrm{H}_{2} \mathrm{O}$.

Since our strategy based on radiation chemistry was opened up to the preparation of various CPs, we would like to develop the fabrication of new conducting materials by the way of radiation induced copolymerization. The purpose is to adjust and enhance the properties of the copolymers by varying the chemical nature of the organic monomers, by fine-tuning their distribution along the polymer backbone and by increasing the polymer chain length. This work is in progress. Also, we would like to extend our methodology to the preparation of conducting polymers in water/dichloromethane microemulsions. The purpose is to control the morphology of the as-prepared materials, to increase their chain length and to adjust their optical and electrical properties.

\section{Conflicts of interest}

There are no conflicts to declare.

\section{Acknowledgements}

We thank Romuald Saint-Martin (ICMMO, Université Paris-Sud, France) for XRD analysis and Jean-Michel Guignier (IMPMC, Université Pierre et Marie Curie, France) for Cryo-TEM experiments.

\section{References}

1 T. A. Skotheim and J. Reynolds, Conjugated Polymers: Processing and Applications, CRC Press, 3rd edn, 2007.

2 A. J. Heeger, J. Phys. Chem., 2001, 105, 8476-8491.

3 C. K. Chiang, S. C. Gau, C. R. Fincher, Y. W. Park, A. G. Macdiarmid and A. J. Heeger, Appl. Phys. Lett., 1978, 33, 18-20.

4 H. Ohkita and S. Ito, Polymer, 2011, 52, 4397-4417.

5 A. Mishra, C. Q. Ma and P. Bauerle, Chem. Rev., 2009, 109, 1141-1276.

6 A. K. Wanekaya, M. A. Bangar, M. Yun, W. Chen, N. V. Myung and A. Mulchandani, J. Phys. Chem. C, 2007, 111, 5218-5221.

7 Y. Lattach, N. Fourati, C. Zerrouki, J. M. Fougnion, F. Garnier, C. Pernelle and S. Remita, Electrochim. Acta, 2012, 73, 36-44. 
8 C. Jiang, G. Chen and X. Wang, Synth. Met., 2012, 162, 1968-1971.

9 R. Sugimoto, S. Takeda, H. B. Gu and K. Yoshino, Chem. Express, 1986, 1, 635-638.

10 J. Roncali, Chem. Rev., 1992, 92, 711-738.

11 X. T. Zhang, J. Zhang, W. H. Song and Z. F. Liu, J. Phys. Chem. B, 2006, 110, 1158-1165.

12 C. R. Siju, K. Narasimha Rao, R. Ganesan, E. S. R. Gopal and S. Sindhu, Phys. Status Solidi C, 2011, 8, 2739-2741.

13 H. Zhou, G. Han, Y. Chang, D. Fu and Y. Xiao, J. Power Sources, 2015, 274, 229-236.

14 B. Gupta, M. Mehta, A. Melvin, R. Kamalakannan, S. Dash, M. Kamruddin and A. K. Tyagi, Mater. Chem. Phys., 2014, 147, 867-877.

15 X. Zhang, J.-S. Lee, G. S. Lee, D.-K. Cha, M. J. Kim, D. J. Yang and S. K. Manohar, Macromolecules, 2006, 39, 470-472.

16 J. Jang and H. Yoon, Langmuir, 2005, 21, 11484-11489.

17 W. Choi, T. An and G. Lim, Fabrication of conducting polymer nanowire sensor array, Sensors, IEEE, 2009, pp. 1151-1153.

18 J. Jang, M. Chang and H. Yoon, Adv. Mater., 2005, 17, 1616-1620.

19 J. Huang, Pure Appl. Chem., 2006, 78, 15.

20 M. Aydın, Z. Durmus, H. Kavas, B. Esat, H. Sözeri, A. Baykal, F. Yllmaz and M. S. Toprak, Polyhedron, 2011, 30, 1120-1126.

21 Z. Cui, C. Coletta, T. Bahry, J.-L. Marignier, J.-M. Guigner, M. Gervais, S. Baiz, F. Goubard and S. Remita, Mater. Chem. Front., 2017, 1, 879-892.

22 X. Yuan, D. Floresyona, P.-H. Aubert, T.-T. Bui, S. Remita, S. Ghosh, F. Brisset, F. Goubard and H. Remita, Appl. Catal., $B, 2019,242,284-292$.

23 D. Floresyona, F. Goubard, P.-H. Aubert, I. Lampre, J. Mathurin, A. Dazzi, S. Ghosh, P. Beaunier, F. Brisset, S. Remita, L. Ramos and H. Remita, Appl. Catal., B, 2017, 209, 23-32.

24 S. Ghosh, H. Remita, L. Ramos, A. Dazzi, A. DenisetBesseau, P. Beaunier, F. Goubard, P.-H. Aubert, F. Brisset and S. Remita, New J. Chem., 2014, 38, 1106-1115.

25 Y. Lattach, A. Deniset-Besseau, J.-M. Guigner and S. Remita, Radiat. Phys. Chem., 2013, 82, 44-53.

26 Y. Lattach, C. Coletta, S. Ghosh and S. Remita, ChemPhysChem, 2014, 15, 208-218.

27 Z. Cui, C. Coletta, R. Rebois, S. Baiz, M. Gervais, F. Goubard, P.-H. Aubert, A. Dazzi and S. Remita, Radiat. Phys. Chem., 2016, 119, 157-166.

28 Z. Cui, C. Coletta, A. Dazzi, P. Lefrançois, M. Gervais, S. Néron and S. Remita, Langmuir, 2014, 30, 14086-14094.

29 C. Coletta, Z. Cui, A. Dazzi, J.-M. Guigner, S. Néron, J.-L. Marignier and S. Remita, Radiat. Phys. Chem., 2016, 126, 21-31.

30 C. Coletta, Z. Cui, P. Archirel, P. Pernot, J.-L. Marignier and S. Remita, J. Phys. Chem. B, 2015, 119, 5282-5298.

31 T. Bahry, Z. Cui, A. Deniset-Besseau, M. Gervais, C. Sollogoub, T.-T. Bui and S. Remita, New J. Chem., 2018, 42, 8704-8716.

32 S. S. Emmi, G. Beggiato and G. Casalbore-Miceli, Int. J. Radiat. Appl. Instrum., Part C, 1989, 33, 29-37.
33 T. Wu, L. Wang, Y. Zhang, S. Du, W. Guo and M. Pei, RSC Adv., 2015, 5, 16684-16690.

34 P. S. Tóth, C. Janáky, Z. Hiezl and C. Visy, Electrochim. Acta, 2011, 56, 3447-3453.

35 C. Janáky, C. Visy, O. Berkesi and E. Tombácz, J. Phys. Chem. C, 2009, 113, 1352-1358.

36 Y. Jiang, Y. Shen and P. Wu, J. Colloid Interface Sci., 2008, 319, 398-405.

37 S. Yanagida, G. K. R. Senadeera, K. Nakamura, T. Kitamura and Y. Wada, J. Photochem. Photobiol., A, 2004, 166, 75-80.

38 B. Kim, L. Chen, J. Gong and Y. Osada, Macromolecules, 1999, 32, 3964-3969.

39 H. S. O. Chan, C.-S. Toh and L.-M. Gan, J. Mater. Chem., 1995, 5, 631-637.

40 R. D. McCullough, P. C. Ewbank and R. S. Loewe, J. Am. Chem. Soc., 1997, 119, 633-634.

41 P. Najafisayar and M. E. Bahrololoom, Electrochim. Acta, 2013, 114, 462-473.

42 M.-a. Sato, S. Tanaka and K. Kaeriyama, J. Chem. Soc., Chem. Commun., 1985, 713-714, DOI: 10.1039/c39850000713.

43 A. J. Downard and D. Pletcher, J. Electroanal. Chem. Interfacial Electrochem., 1986, 206, 139-145.

44 Z. B. Alfassi, S. Mosseri and P. Neta, J. Phys. Chem., 1989, 93, 1380-1385.

45 S. S. Emmi, M. D’Angelantonio, G. Beggiato, G. Poggi, A. Geri, D. Pietropaolo and G. Zotti, Radiat. Phys. Chem., 1999, 54, 263-270.

46 J. W. T. Spinks and R. J. Woods, An Introduction to Radiation Chemistry, John Wiley \& Sons, Inc., New York, 1990, vol. 3, pp. 251-256.

47 C. Ferradini and J.-P. Jay-Gerin, Res. Chem. Intermed., 2000, 26, 549-565.

48 C. Ferradini and J.-P. Jay-Gerin, Can. J. Chem., 1999, 77, 1542-1575.

49 E. J. Hart, Acc. Chem. Res., 1969, 2, 161-167.

50 H. A. Schwarz, J. Chem. Educ., 1981, 58, 101-105.

51 Z. Cui, T. Bahry, A. Dazzi, T.-T. Bui, F. Goubard and S. Remita, Radiat. Phys. Chem., 2019, 159, 47-56.

52 A. J. Elliot, S. Geertsen and G. V. Buxton, J. Chem. Soc., Faraday Trans. 1, 1988, 84, 1101-1112.

53 E. J. Beiting, K. J. Zeringue and R. E. Stickel, Spectrochim. Acta, Part A, 1985, 41, 1413-1418.

54 A. L. Gomes, M. B. Pinto Zakia, J. G. Filho, E. Armelin, C. Alemán and J. Sinezio de Carvalho Campos, Polym. Chem., 2012, 3, 1334-1343.

55 T. Kim, J. Kim, Y. Kim, T. Lee, W. Kim and K. S. Suh, Curr. Appl. Phys., 2009, 9, 120-125.

56 Y. He, W.-j. Guo, M.-s. Pei and G.-y. Zhang, Chin. J. Polym. Sci., 2012, 30, 537-547.

57 A. C. Carreon, W. L. Santos, J. B. Matson and R. C. So, Polym. Chem., 2014, 5, 314-317.

58 A. Shit and A. K. Nandi, Phys. Chem. Chem. Phys., 2016, 18, 10182-10190.

59 A. de França Mescoloto, S. H. Pulcinelli, C. Santilli and V. Cristina Gonçalves, Polimeros, 2014, 24, 31-35. 
60 M. Giglioti, F. Strixino, J. T. Matsushima, L. Bulhoes and E. Pereira, Sol. Energy Mater. Sol. Cells, 2004, 82, 413-420.

61 R. Ben Ishay, Y. Harel, R. Lavi and J.-P. Lellouche, RSC Adv., 2016, 6, 89585-89598.

62 J. Pommerehne, H. Vestweber, W. Guss, R. F. Mahrt, H. Bässler, M. Porsch and J. Daub, Adv. Mater., 1995, 7, 551-554.
63 R. Fernando and G. K. R. Senadeera, Curr. Sci., 2008, 95, 743-750.

64 J. Tauc, Mater. Res. Bull., 1968, 3, 37-46.

65 E. A. Davis and N. F. Mott, Philos. Mag. A, 1970, 22, 0903-0922.

66 H. Kohjiro, S. Kazuhiro and A. Hironori, Bull. Chem. Soc. Jpn., 2000, 73, 583-587. 